\title{
Mathematics of the total alkalinity-pH equation - pathway to robust and universal solution algorithms: the SolveSAPHE package v1.0.1
}

\author{
G. Munhoven \\ Département d'Astrophysique, Géophysique et Océanographie, Université de Liège, 4000 Liège, Belgium \\ Correspondence to: G. Munhoven (guy.munhoven@ulg.ac.be)
}

Received: 21 February 2013 - Published in Geosci. Model Dev. Discuss.: 12 March 2013

Revised: 17 June 2013 - Accepted: 8 July 2013 - Published: 30 August 2013

\begin{abstract}
The total alkalinity-pH equation, which relates total alkalinity and $\mathrm{pH}$ for a given set of total concentrations of the acid-base systems that contribute to total alkalinity in a given water sample, is reviewed and its mathematical properties established. We prove that the equation function is strictly monotone and always has exactly one positive root. Different commonly used approximations are discussed and compared. An original method to derive appropriate initial values for the iterative solution of the cubic polynomial equation based upon carbonate-borate-alkalinity is presented. We then review different methods that have been used to solve the total alkalinity-pH equation, with a main focus on biogeochemical models. The shortcomings and limitations of these methods are made out and discussed. We then present two variants of a new, robust and universally convergent algorithm to solve the total alkalinity- $\mathrm{pH}$ equation. This algorithm does not require any a priori knowledge of the solution. SolveSAPHE (Solver Suite for Alkalinity-PH Equations) provides reference implementations of several variants of the new algorithm in Fortran 90, together with new implementations of other, previously published solvers. The new iterative procedure is shown to converge from any starting value to the physical solution. The extra computational cost for the convergence security is only 10-15\% compared to the fastest algorithm in our test series.
\end{abstract}

\section{Introduction}

Biogeochemical models have become indispensable tools to improve our understanding of the cycling of the elements in the Earth system. A central and critical component of almost all biogeochemical models is the $\mathrm{pH}$ calculation routine. In ocean carbon cycle models, the air-sea exchange of $\mathrm{CO}_{2}$ is directly linked to the surface ocean $\left[\mathrm{CO}_{2}\right]$; the preservation of biogenic carbonates in the surface sediments at the sea floor is closely linked to the deep sea $\left[\mathrm{CO}_{3}^{2-}\right]$ (Broecker and Peng, 1982). The fractions of $\mathrm{CO}_{2}, \mathrm{HCO}_{3}^{-}$and $\mathrm{CO}_{3}^{2-}$ in the total dissolved inorganic carbon (i.e. the speciation of the carbonate system) are controlled by $\mathrm{pH}$. Hence, $\mathrm{pH}$ changes in seawater may directly influence air-sea exchange of $\mathrm{CO}_{2}$ or the preservation of carbonates in the deep sea. Conversely, the dissociation of acids, such as carbonic acid, also controls $\mathrm{pH}$ : when the ocean takes up or releases $\mathrm{CO}_{2}$ (e.g. as a result of a rise or a decline of the abundance of $\mathrm{CO}_{2}$ in the atmosphere), its $\mathrm{pH}$ changes. The currently ongoing ocean acidification due to the massive release of $\mathrm{CO}_{2}$ into the atmosphere by human activity is but one example of such an induced $\mathrm{pH}$ change.

The nitrogen cycle is another important biogeochemical cycle where $\mathrm{pH}$ plays an important role. The speciation of dissolved ammonium is - as that of any acid-base system dependent on $\mathrm{pH}, \mathrm{NH}_{3}$ being more abundant than $\mathrm{NH}_{4}^{-}$at high $\mathrm{pH}$, and less abundant at low $\mathrm{pH}$. At $\mathrm{pH}>9$, the concentration of $\mathrm{NH}_{3}$ in seawater may reach toxic levels. 
The realistic modelling of biologically mediated fluxes (e.g. marine primary or export production) requires the colimitation or even inhibition by different chemical components to be taken into account. The nitrogen and carbon cycles, already mentioned above, strongly interact, both in the ocean and on land. In the ocean, $\mathrm{Fe}$ and other metals act as micronutrients and once again, $\mathrm{pH}$ plays an important role as the solubility of metals is strongly dependent on $\mathrm{pH}$ (Millero et al., 2009). The resulting coupling of the biogeochemical cycles of different elements makes biogeochemical models become more and more complex and $\mathrm{pH}$ calculation more and more difficult.

Biogeochemical models are now increasingly used for settings that are strongly different from present day. Typical applications include future ocean acidification (e.g. Caldeira and Wickett, 2003), the Paleocene-Eocene Thermal Maximum (e.g. Ridgwell and Schmidt, 2010), Snowball Earth (e.g. Le Hir et al., 2009), etc. Some commonly used pH solvers may possibly become unstable and produce unreliable results. The convergence properties of currently used solution methods has actually never been systematically tested.

Unfortunately, information on $\mathrm{pH}$ solver failures is only seldom published. Zeebe (2012) reports for his LOSCAR model that negative $\mathrm{H}^{+}$concentrations may be obtained when starting with total alkalinity and dissolved inorganic carbon concentrations in a very high ratio, requiring the model run to be restarted with the respective concentrations in a lower ratio. Hofmann et al. (2010) also indicate that the standard $\mathrm{pH}$ solving routine in their $\mathrm{R}$ modelling environment AquaEnv may fail when trying to calculate the $\mathrm{pH}$ for samples with very low or zero dissolved inorganic carbon concentrations. In this case, they resort to a general purpose interval based root finding routine instead, adopting a very large bracketing interval (see Hofmann et al., 2012), possibly leading to a considerable performance loss. Andy Ridgwell, in his editorial comment to the companion discussion paper, mentions convergence problems encountered with the GENIE model code (Ridgwell et al., 2007) encountered while studying the effect of an artificial addition of lime $(\mathrm{CaO})$ to the ocean surface (a particular geoengineering method meant to accelerate the uptake of carbon dioxide from the atmosphere) once total alkalinity came to exceed the typical surface ocean concentrations of dissolved inorganic carbon by about a factor of two. As we will show below, the three models use essentially equivalent $\mathrm{pH}$ calculation methods, which become divergent under those typical conditions.

The speciation of any acid system, i.e. the determination of the concentrations of each one of the undissociated and the different dissociated forms of an acid, is an underdetermined problem if only the total concentration and thermodynamic or stoichiometric constants are known. This underdetermination can be lifted if $\mathrm{pH}$ is known. Being dependent on temperature and pressure, neither $\mathrm{pH}$ nor $\left[\mathrm{H}^{+}\right]$are, however, well suitable for being used in transport equations, and thus in biogeochemical models. In biogeochemical models, the common way to resolve this underdetermination is to consider another conservative quantity: total alkalinity, also called titration alkalinity. Total alkalinity, which is also an experimentally measurable quantity, ties all the different acid systems present in a water sample together and allows us to solve the speciation problem. In comparison to $\mathrm{pH}$, it has the advantage of being a conservative quantity: it is only controlled by its sources and sinks, and it is independent on temperature and pressure (Zeebe and Wolf-Gladrow, 2001).

In the following section, we provide a comprehensive introduction to the concept of alkalinity. In our exploration of the mathematical properties of the equation that relates $\left[\mathrm{H}^{+}\right]$ to total alkalinity start with a detailed presentation of various approximations commonly used for present-day seawater. The analysis of the mathematical properties of these approximations will provide useful hints for the characteristics of the general case. In Sect. 3 of this paper, we present solution methods for deriving $\mathrm{pH}$ from each of the various approximations to total alkalinity considered. Complications that might possibly arise from the various $\mathrm{pH}$ scales that are in use in marine chemistry are elucidated in Sect. 4. In Sect. 5, we then show that there are intrinsic bounds that bracket the root of the total alkalinity-pH equation, and that can be directly derived from the approximation used to represent total alkalinity. The existence of such bounds makes it possible to define a new, universal algorithm to solve the alkalinity-pH equation, which requires no a priori knowledge of the root. A reference implementation of two variants of the new algorithm is presented in Sect. 6. The algorithms are tested for their efficiency and robustness and their performance compared with that of the most common previously published general solution methods.

\section{Total alkalinity: general definition and approximations}

In the following parts of this section, we review a number of aspects of total alkalinity in natural waters. The main focus will be put onto seawater and on the carbonate system, but all the presented developments can be applied to any natural water sample, provided the required thermodynamic constants are known. We briefly recall the different approximations commonly used for calculating $\mathrm{pH}$ and the speciation of acid systems. We will then establish a few basic properties of the expressions that relate the various types of alkalinity to total concentrations and $\mathrm{pH}$. Although simple, these properties do not seem to have been previously explored in detail, nor exploited for designing methods of solution of the alkalinity-pH equation.

Although we primarily focus on modelling in the following developments, the calculation procedures are obviously also applicable in experimental set-ups. 


\subsection{Total alkalinity}

\subsubsection{General definition}

Total alkalinity, also called titration alkalinity, denoted here $\mathrm{Alk}_{\mathrm{T}}$, reflects the excess of chemical bases of the solution relative to an arbitrary specified zero level of protons, or equivalence point. Ideally, $\mathrm{Alk}_{\mathrm{T}}$ represents the amount of bases contained in a sample of seawater that will accept a proton when the sample is titrated with a strong acid (e.g. hydrochloric acid) to the carbonic acid endpoint. That endpoint is located at the $\mathrm{pH}$ below which $\mathrm{H}^{+}$ions get more abundant in solution than $\mathrm{HCO}_{3}^{-}$ions; its value is close to 4.5 . $\mathrm{H}^{+}$added to water at this $\mathrm{pH}$ by adding strong acid will remain as such in solution. Please notice that, for the sake of a simpler notation, we follow here the common usage of denoting protons in solution by $\mathrm{H}^{+}$, although free $\mathrm{H}^{+}$ions sensu stricto do only exist in insignificantly small amounts in aqueous solutions. Each proton is rather bound to a water molecule to form an $\mathrm{H}_{3} \mathrm{O}^{+}$ ion, and each of these $\mathrm{H}_{3} \mathrm{O}^{+}$in turn is furthermore generally hydrogen bonded to three other $\mathrm{H}_{2} \mathrm{O}$ molecules to form an $\mathrm{H}_{9} \mathrm{O}_{4}^{+}$ion (Dickson, 1984).

Rigorously speaking, $\mathrm{Alk}_{\mathrm{T}}$ is defined as the number of moles of $\mathrm{H}^{+}$ions equivalent to the excess of "proton acceptors", i.e. bases formed from acids characterized by a $p K_{\mathrm{A}} \geq$ 4.5 in a solution of zero ionic strength at $25^{\circ} \mathrm{C}$, over "proton donors", i.e. acids with $p K_{\mathrm{A}}<4.5$ under the same conditions, per kilogram of sample (Dickson, 1981).

With emphasis on the most important contributors, a rather complete expression for $\mathrm{Alk}_{\mathrm{T}}$ in a seawater sample is

$$
\begin{aligned}
\mathrm{Alk}_{\mathrm{T}}= & {\left[\mathrm{HCO}_{3}^{-}\right]+2 \times\left[\mathrm{CO}_{3}^{2-}\right]+\left[\mathrm{B}(\mathrm{OH})_{4}^{-}\right]+\left[\mathrm{OH}^{-}\right] } \\
& +\left[\mathrm{HPO}_{4}^{2-}\right]+2 \times\left[\mathrm{PO}_{4}^{3-}\right]+\left[\mathrm{H}_{3} \mathrm{SiO}_{4}^{-}\right] \\
& +\left[\mathrm{NH}_{3}\right]+\left[\mathrm{HS}^{-}\right]+2 \times\left[\mathrm{S}^{2-}\right]+\ldots \\
& -\left[\mathrm{H}^{+}\right]_{\mathrm{f}}-\left[\mathrm{HSO}_{4}^{-}\right]-[\mathrm{HF}]-\left[\mathrm{H}_{3} \mathrm{PO}_{4}\right]-\ldots,
\end{aligned}
$$

where the ellipses refer to other potential proton donors and acceptors generally present at negligible concentrations only. All of the concentrations are total concentrations (which include free, hydrated and complexed forms of the individual species), except for $\left[\mathrm{H}^{+}\right]_{\mathrm{f}}$, which only includes the free and hydrated forms. There are alternative definitions that can be found in the literature, which lead to similar, although not necessarily exactly the same, expressions. However, the above definition is the one that reflects the titration procedure used to measure alkalinity the most accurately. We will therefore base the following developments upon it.

In other natural water samples (lake, river, or brines) the constituent list in Eq. (1) needs to be adapted: some constituents may be neglected and bases of other acid systems have to be included (e.g. bases derived from organic acids, from dissolved metals, etc.). While total alkalinity in seawater samples typically ranges between about 2 and $2.6 \mathrm{meq} \mathrm{kg}^{-1}$, acid mine drainage samples may even present negative alkalinity, representing the fact that a strong base instead of a strong acid must be added to reach the equivalence $\mathrm{pH}$ point of 4.5. Interested readers may refer, e.g. to Kirby and Cravotta III (2005) and references therein for such - from a marine chemist's point of view - exotic samples.

\subsubsection{The pH-total alkalinity equation}

Total alkalinity as defined above is a conservative quantity with respect to mixing, changes in temperature and pressure (Wolf-Gladrow et al., 2007). It is therefore a cornerstone in biogeochemical cycle models which are most conveniently formulated on the basis of conservation equations. In such models, definition/Eq. (1) above, or an adequate variant, is used to solve the inverse problem for $\left[\mathrm{H}^{+}\right]$. All of the individual species concentrations appearing in Eq. (1) can be expressed in terms of the total concentrations of the acid systems that they respectively belong to and of $\left[\mathrm{H}^{+}\right]$. Given the evolutions of the total concentrations of all the acid systems considered (dissociated and non-dissociated forms) and of $\mathrm{Alk}_{\mathrm{T}}$ - all of which can be derived from appropriate conservation equations - expression (1) is interpreted as an equation for $\left[\mathrm{H}^{+}\right]$or, equivalently, $\mathrm{pH}$. We will therefore call that equation the total alkalinity-pH equation.

We might actually have called our equation simply the $\mathrm{pH}$ equation. Alk $\mathrm{K}_{\mathrm{T}}$ does indeed not play any special or more important role than any of the total concentrations of the other acid systems considered. We do, however, feel that this name would have been too general and thus prefer to include "total alkalinity" in the name to reflect that the overall structure of the equation derives from the definition of total alkalinity.

\subsubsection{Typical applications in biogeochemical models}

In a typical global ocean carbon cycle model, total alkalinity may commonly be approximated by

$\mathrm{Alk}_{\mathrm{T}} \simeq\left[\mathrm{HCO}_{3}^{-}\right]+2 \times\left[\mathrm{CO}_{3}^{2-}\right]+\left[\mathrm{B}(\mathrm{OH})_{4}^{-}\right]+\left[\mathrm{OH}^{-}\right]-\left[\mathrm{H}^{+}\right]$,

where $\left[\mathrm{H}^{+}\right] \simeq\left[\mathrm{H}^{+}\right]_{\mathrm{f}}+\left[\mathrm{HSO}_{4}^{-}+[\mathrm{HF}]\right.$. $\left[\mathrm{HCO}_{3}^{-}\right]$and $\left[\mathrm{CO}_{3}^{2-}\right]$ can be expressed as a function of the total concentration of dissolved inorganic carbon, $C_{\mathrm{T}}$, and $\left[\mathrm{H}^{+}\right]$(see Sect. 2.2.1 for details) while $\left[\mathrm{B}(\mathrm{OH})_{4}^{-}\right]$can be expressed as a function of the total borate concentration, $B_{\mathrm{T}}$, and $\left[\mathrm{H}^{+}\right]$(see Sect. 2.2.2 for details); $\left[\mathrm{OH}^{-}\right]$is directly linked to $\left[\mathrm{H}^{+}\right]$via the equilibrium constant for the dissociation of water. Accordingly, Eq. (2) provides a relationship between $C_{\mathrm{T}}, B_{\mathrm{T}}, \mathrm{Alk}_{\mathrm{T}}$ and $\left[\mathrm{H}^{+}\right]$(i.e. $\mathrm{pH}$ ). The model provides conservation equations for $C_{\mathrm{T}}$ and $\mathrm{Alk}_{\mathrm{T}} ; B_{\mathrm{T}}$ can generally be taken proportional to salinity, whose evolution either follows a prescribed scenario or may also derived from a conservation equation. Relationship (2) thus reduces to an equation in $\left[\mathrm{H}^{+}\right]$. The solution of that equation finally provides a means to calculate the complete speciation of the carbonate and the borate systems.

In other biogeochemical studies where other systems than the carbonate system are of interest (such as ammonium, sulphides, etc.), the procedure is entirely analogue. Each one 
of the individual species concentrations that need to be considered in Eq. (1) for that particular application is expressed in terms of the total concentration of the acid system that it belongs to and conservation equations, scenarios or measurements that are used to evaluate all of the total concentrations, including total alkalinity. These steps again reduce Eq. (1) into an equation in $\left[\mathrm{H}^{+}\right]$, whose solution provides a direct means to calculate the speciations of all the systems considered.

\subsection{Common approximations for total alkalinity in seawater}

Here we first analyse the forward problem for a few specific approximations used for seawater: for given total concentrations of dissolved inorganic carbon, total borate, etc., we analyse how the expressions for the different types of alkalinity change as a function of $\left[\mathrm{H}^{+}\right]$. This simple analysis will already provide valuable insight into the overall mathematical properties of the total alkalinity-pH equation and its subcomponents, which we can exploit later for the most general case.

\subsubsection{Carbonate alkalinity}

The contribution of the carbonic acid system (or carbonate system) to total alkalinity is called carbonate alkalinity and we denote it by $\mathrm{Alk}_{\mathrm{C}}$ :

$\mathrm{Alk}_{\mathrm{C}}=\left[\mathrm{HCO}_{3}^{-}\right]+2\left[\mathrm{CO}_{3}^{2-}\right]$.

Upon substitution of the concentrations of the species by their fractional expressions as a function of $\left[\mathrm{H}^{+}\right]$,

$\left[\mathrm{HCO}_{3}^{-}\right]=C_{\mathrm{T}} \frac{K_{1}\left[\mathrm{H}^{+}\right]}{\left[\mathrm{H}^{+}\right]^{2}+K_{1}\left[\mathrm{H}^{+}\right]+K_{1} K_{2}}$

and

$$
\left[\mathrm{CO}_{3}^{2-}\right]=C_{\mathrm{T}} \frac{K_{1} K_{2}}{\left[\mathrm{H}^{+}\right]^{2}+K_{1}\left[\mathrm{H}^{+}\right]+K_{1} K_{2}},
$$

where $C_{\mathrm{T}}$ is the total concentration of dissolved inorganic carbon $\left(C_{\mathrm{T}}=\left[\mathrm{CO}_{2}\right]+\left[\mathrm{HCO}_{3}^{-}\right]+\left[\mathrm{CO}_{3}^{2-}\right]\right), K_{1}$ and $K_{2}$ are the first and second dissociation constant for carbonic acid, we get

$$
\mathrm{Alk}_{\mathrm{C}}=C_{\mathrm{T}} \frac{K_{1}\left[\mathrm{H}^{+}\right]+2 K_{1} K_{2}}{\left[\mathrm{H}^{+}\right]^{2}+K_{1}\left[\mathrm{H}^{+}\right]+K_{1} K_{2}} .
$$

For constant $C_{\mathrm{T}}$, the right-hand side is a strictly decreasing function of $\left[\mathrm{H}^{+}\right]$: its derivative with respect to $\left[\mathrm{H}^{+}\right]$is strictly negative for positive $\left[\mathrm{H}^{+}\right]$. As a consequence, $0<\mathrm{Alk}_{\mathrm{C}}<$ $2 C_{\mathrm{T}}$ if $C_{\mathrm{T}} \neq 0$. Both bounds are strict (i.e. they cannot be reached) and represent the limits of $\operatorname{Alk}_{\mathrm{C}}\left(C_{\mathrm{T}} ;\left[\mathrm{H}^{+}\right]\right)$for $\left[\mathrm{H}^{+}\right] \rightarrow+\infty$ (lower bound) and $\left[\mathrm{H}^{+}\right] \rightarrow 0$ (upper bound), for $C_{\mathrm{T}}$ fixed.

\subsubsection{Carbonate and borate alkalinity}

The second most important component of natural presentday seawater alkalinity is borate alkalinity, $\mathrm{Alk}_{\mathrm{B}}$. Together with the carbonate alkalinity we have

$$
\mathrm{Alk}_{\mathrm{CB}}=\mathrm{Alk}_{\mathrm{C}}+\mathrm{Alk}_{\mathrm{B}}=\left[\mathrm{HCO}_{3}^{-}\right]+2\left[\mathrm{CO}_{3}^{2-}\right]+\left[\mathrm{B}(\mathrm{OH})_{4}^{-}\right] .
$$

Upon substitution of the individual species concentrations by their fractional expressions as a function of $\left[\mathrm{H}^{+}\right]$, we get

$$
\mathrm{Alk}_{\mathrm{CB}}=C_{\mathrm{T}} \frac{K_{1}\left[\mathrm{H}^{+}\right]+2 K_{1} K_{2}}{\left[\mathrm{H}^{+}\right]^{2}+K_{1}\left[\mathrm{H}^{+}\right]+K_{1} K_{2}}+B_{\mathrm{T}} \frac{K_{\mathrm{B}}}{\left[\mathrm{H}^{+}\right]+K_{\mathrm{B}}},
$$

where $B_{\mathrm{T}}$ is the total concentration of dissolved borates and $K_{\mathrm{B}}$ is the dissociation constant for boric acid. For constant $B_{\mathrm{T}}$, Alk $\mathrm{k}_{\mathrm{B}}$ is again a strictly decreasing function with $\left[\mathrm{H}^{+}\right]$, similarly to Alk $\mathrm{C}_{\mathrm{C}}$. Hence, for constant $C_{\mathrm{T}}$ and $B_{\mathrm{T}}$, Alk $\mathrm{AB}_{\mathrm{CB}}$ is a strictly decreasing function with $\left[\mathrm{H}^{+}\right]$and, as a consequence, $0<\mathrm{Alk}_{\mathrm{CB}}<2 C_{\mathrm{T}}+B_{\mathrm{T}}$ as long as $C_{\mathrm{T}}+B_{\mathrm{T}} \neq 0$.

\subsubsection{Carbonate, borate and water self-ionization alkalinity}

In a third stage, we may consider the alkalinity that arises from the dissociation of the solvent water itself (by self-ionization) in addition to carbonate and borate alkalinity and get the next important approximation for natural present-day seawater, called practical alkalinity by Zeebe and Wolf-Gladrow (2001):

$$
\begin{aligned}
& \text { Alk }_{\mathrm{CBW}} \\
& =\mathrm{Alk}_{\mathrm{CB}}+\left[\mathrm{OH}^{-}\right]-\left[\mathrm{H}^{-}\right] \\
& =\left[\mathrm{HCO}_{3}^{-}\right]+2\left[\mathrm{CO}_{3}^{2-}\right]+\left[\mathrm{B}(\mathrm{OH})_{4}^{-}\right]+\left[\mathrm{OH}^{-}\right]-\left[\mathrm{H}^{+}\right] .
\end{aligned}
$$

Upon substitution by the respective speciation relationships, we get

$$
\begin{aligned}
\operatorname{Alk}_{\mathrm{CBW}}= & C_{\mathrm{T}} \frac{K_{1}\left[\mathrm{H}^{+}\right]+2 K_{1} K_{2}}{\left[\mathrm{H}^{+}\right]^{2}+K_{1}\left[\mathrm{H}^{+}\right]+K_{1} K_{2}} \\
& +B_{\mathrm{T}} \frac{K_{\mathrm{B}}}{\left[\mathrm{H}^{+}\right]+K_{\mathrm{B}}}+\frac{K_{\mathrm{W}}}{\left[\mathrm{H}^{+}\right]}-\left[\mathrm{H}^{+}\right],
\end{aligned}
$$

where $K_{\mathrm{W}}$ is the dissociation constant of water in seawater. At this stage, we do not want to insist on subtleties related to $\mathrm{pH}$ scales. Normally, the last term $\left[\mathrm{H}^{+}\right]$in the two previous equations should actually read $\left[\mathrm{H}^{+}\right]_{\mathrm{f}}$. We will address the difference between $\left[\mathrm{H}^{+}\right]$and $\left[\mathrm{H}^{+}\right]_{\mathrm{f}}$ in Sect. 4 below.

Since $\mathrm{Alk}_{\mathrm{CB}}$ is decreasing with $\left[\mathrm{H}^{+}\right]$, for constant $C_{\mathrm{T}}$ and $B_{\mathrm{T}}$, the same holds for $\mathrm{Alk}_{\mathrm{CBW}}$, because $K_{\mathrm{W}} /\left[\mathrm{H}^{+}\right]-\left[\mathrm{H}^{+}\right]$ is again decreasing with $\left[\mathrm{H}^{+}\right]$. However, unlike $\mathrm{Alk}_{\mathrm{CB}}$, Alk $\mathrm{CBW}_{\mathrm{C}}$ is unbounded and it can take arbitrarily low values (for $\left[\mathrm{H}^{+}\right] \gg$ ) and arbitrarily great values (for $\left[\mathrm{H}^{+}\right] \ll$ ). 


\subsubsection{Contribution of a generic acid system to total alkalinity}

In common seawater, $\mathrm{Alk}_{\mathrm{CBW}}$ is entirely sufficient even for applications that require high accuracy. However, in some cases other systems than the carbonate and borate systems need to be considered. This is especially the case in suboxic and anoxic waters, such as semi-closed fjords (e.g. Framvaren Fjord in Norway studied by Yao and Millero, 1995) or at a larger scale, the Black Sea (e.g. Dyrssen, 1999), where, e.g. the contribution from sulphides cannot be neglected.

In order to generalize our analysis of the total alkalinity$\mathrm{pH}$ equation, let us consider a generic acid, denoted by $\mathrm{H}_{n} \mathrm{~A}$, that may potentially lead to $n$ successive dissociation reactions, characterized by stoichiometric dissociation constants $K_{1}, K_{2}, \ldots, K_{n}$, respectively:

$$
\begin{array}{cc}
\mathrm{H}_{n} \mathrm{~A} \rightleftharpoons \mathrm{H}^{+}+\mathrm{H}_{n-1} \mathrm{~A}^{-}, & K_{1}=\frac{\left[\mathrm{H}^{+}\right]\left[\mathrm{H}_{n-1} \mathrm{~A}^{-}\right]}{\left[\mathrm{H}_{n} \mathrm{~A}\right]} \\
\mathrm{H}_{n-1} \mathrm{~A}^{-} \rightleftharpoons \mathrm{H}^{+}+\mathrm{H}_{n-2} \mathrm{~A}^{2-}, & K_{2}=\frac{\left[\mathrm{H}^{+}\right]\left[\mathrm{H}_{n-2} \mathrm{~A}^{2-}\right]}{\left[\mathrm{H}_{n-1} \mathrm{~A}^{-}\right]} \\
\vdots & \vdots \\
\mathrm{HA}^{(n-1)-} \rightleftharpoons \mathrm{H}^{+}+\mathrm{A}^{n-}, & K_{n}=\frac{\left[\mathrm{H}^{+}\right]\left[\mathrm{A}^{n-}\right]}{\left[\mathrm{HA}^{(n-1)-}\right]} .
\end{array}
$$

For simplicity, we omit the " $*$ " superscript commonly used elsewhere to differentiate stoichiometric from thermodynamic dissociation constants (i.e. elsewhere stoichiometric constants generally write $K_{i}^{*}$ instead of $K_{i}$ ). Throughout this paper, the constants used will relate concentrations and not activities. As such, they include the effect of activity coefficients that differ from unity. The values of such constants not only depend on temperature and pressure but also on the ionic strength of the solution. Everything developed here furthermore applies to all kinds of acids, be they of Arrhenius, Brønsted-Lowry, Lewis or any other type, even if the adopted notation could possibly suggest that our developments only apply to Arrhenius-type acids.
If we denote the total concentration of dissolved acid $\mathrm{H}_{n} \mathrm{~A}$ by $[\Sigma \mathrm{A}]=\left[\mathrm{H}_{n} \mathrm{~A}\right]+\ldots+\left[\mathrm{A}^{n-}\right]$, the fractions of undissociated acid and of the various dissociated forms $\mathrm{H}_{n-1} \mathrm{~A}^{-}$, $\mathrm{H}_{n-2} \mathrm{~A}^{2-}, \ldots, \mathrm{A}^{n-}$ are

$$
\begin{aligned}
\frac{\left[\mathrm{H}_{n} \mathrm{~A}\right]}{[\Sigma \mathrm{A}]} & =\frac{\left[\mathrm{H}^{+}\right]^{n}}{\frac{\left[\mathrm{H}^{+}\right]^{n}+K_{1}\left[\mathrm{H}^{+}\right]^{n-1}+K_{1} K_{2}\left[\mathrm{H}^{+}\right]^{n-2}}{+\ldots+K_{1} K_{2} \cdots K_{n}}} \\
& =\frac{\left[\mathrm{H}^{+}\right]^{n}}{\left[\mathrm{H}^{+}\right]^{n}+\sum_{j=1}^{n}\left[\mathrm{H}^{+}\right]^{n-j} \prod_{i=1}^{j} K_{i}}
\end{aligned}
$$

$$
\frac{\left[\mathrm{H}_{n-1} \mathrm{~A}^{-}\right]}{[\Sigma \mathrm{A}]}=\frac{K_{1}\left[\mathrm{H}^{+}\right]^{n-1}}{\left[\mathrm{H}^{+}\right]^{n}+\sum_{j=1}^{n}\left[\mathrm{H}^{+}\right]^{n-j} \prod_{i=1}^{j} K_{i}},
$$$$
\frac{\left[\mathrm{H}_{n-j} \mathrm{~A}^{j-}\right]}{[\Sigma \mathrm{A}]}=\frac{\left(\prod_{i=1}^{j} K_{i}\right)\left[\mathrm{H}^{+}\right]^{n-j}}{\left[\mathrm{H}^{+}\right]^{n}+\sum_{k=1}^{n}\left[\mathrm{H}^{+}\right]^{n-k} \prod_{i=1}^{k} K_{i}},
$$

$$
\frac{\left[\mathrm{A}^{n-}\right]}{[\Sigma \mathrm{A}]}=\frac{\prod_{i=1}^{n} K_{i}}{\left[\mathrm{H}^{+}\right]^{n}+\sum_{j=1}^{n}\left[\mathrm{H}^{+}\right]^{n-j} \prod_{i=1}^{j} K_{i}} .
$$

The joint contribution of all the different dissociated and nondissociated forms of $\mathrm{H}_{n} \mathrm{~A}$ to alkalinity, proton donors and proton acceptors alike, is then equal to

$$
\mathrm{Alk}_{\mathrm{A}}=\sum_{j=0}^{n}(j-m)\left[\mathrm{H}_{n-j} \mathrm{~A}^{j-}\right],
$$

where $m$ is an integer constant, which is dependant on the socalled zero proton level of the system under consideration:

$$
\begin{aligned}
& \text { - } m \text { is such that } p K_{m}<4.5<p K_{m+1} \text { if } p K_{1}<4.5 \\
& \quad \text { and } p K_{n}>4.5 \\
& -m=0 \text { if } p K_{1}>4.5 \\
& -m=n \text { if } p K_{n}<4.5
\end{aligned}
$$

Since $p K_{m}<4.5$, all of the $\mathrm{H}_{n-j} \mathrm{~A}^{j-}$ in the $\mathrm{H}_{n} \mathrm{~A}-\ldots$ $\mathrm{A}^{n-}$ system for $j=0, \ldots, m-1$ are proton donors: the last one $(j=m-1)$ has a strength of $1 \mathrm{eqmol}^{-1}$, the second to last one $(j=m-2)$ of $2 \mathrm{eq} \mathrm{mol}^{-1}$, etc. Since $p K_{m+1}>4.5$, the dissociation products $\mathrm{H}_{n-j} \mathrm{~A}^{j-}$ for $j=m+1, \ldots, n$ are proton acceptors, the first one $(j=m+1)$ with a strength of 1 eq mol ${ }^{-1}$, the second one $(j=m+2)$ with a strength of $2{\text { eq } \mathrm{mol}^{-1}}^{-1}$, etc. For the carbonic acid system, e.g. $n=2$ and $m=0$; for the boric acid system, $n=1$ and $m=0$; for the phosphoric acid system, $n=3$ and $m=1$. 
From the previous expressions for the species fractions, we then find that

$$
\begin{aligned}
\operatorname{Alk}_{\mathrm{A}}\left(\left[\mathrm{H}^{+}\right]\right) & =[\Sigma \mathrm{A}] \frac{\sum_{j=0}^{n}(j-m) \Pi_{j}\left[\mathrm{H}^{+}\right]^{n-j}}{\sum_{j=0}^{n} \Pi_{j}\left[\mathrm{H}^{+}\right]^{n-j}} \\
& =[\Sigma \mathrm{A}]\left(\frac{\sum_{j=0}^{n} j \Pi_{j}\left[\mathrm{H}^{+}\right]^{n-j}}{\sum_{j=0}^{n} \Pi_{j}\left[\mathrm{H}^{+}\right]^{n-j}}-m\right),
\end{aligned}
$$

where we have defined

$\Pi_{j}=\prod_{i=1}^{j} K_{i}, \quad j=1, \ldots, n \quad$ and $\quad \Pi_{0}=1$

to simplify the notation.

Similar to the carbonate and borate systems above, $\mathrm{Alk}_{\mathrm{A}}$ is strictly decreasing with $\left[\mathrm{H}^{+}\right]$, for $[\Sigma \mathrm{A}]$ fixed. A mathematically rigorous demonstration of this behaviour for the general case is provided in Appendix A.

There are two corollaries of this monotonic behaviour worth emphasizing.

1. For any acid system $\mathrm{H}_{n} \mathrm{~A}-\ldots-\mathrm{A}^{n-}$, $\mathrm{Alk}_{\mathrm{A}}$ is bounded: it has a supremum which is equal to $(n-m)[\Sigma \mathrm{A}]$ (i.e. the limit for $\left[\mathrm{H}^{+}\right] \rightarrow 0$, not actually reachable though), and an infimum, which is equal to $-m[\Sigma \mathrm{A}]$ (i.e. its limit for $\left[\mathrm{H}^{+}\right] \rightarrow+\infty$, also not actually reachable); both of these could, theoretically, be negative if $m$ is sufficiently large.

2. For a water sample that contains a set of acids $\mathrm{H}_{n_{i}} \mathrm{~A}_{[i]}$, $(i=1, \ldots)$ of respective known total concentrations $\left[\Sigma \mathrm{A}_{[i]}\right]$ and with zero proton levels respectively characterized by $m_{i}$, the total alkalinity-pH equation,

$\sum_{i} \operatorname{Alk}_{\mathrm{A}_{[i]}}\left(\left[\mathrm{H}^{+}\right]\right)+\frac{K_{\mathrm{w}}}{\left[\mathrm{H}^{+}\right]}-\left[\mathrm{H}^{+}\right]_{\mathrm{f}}-\mathrm{Alk}_{\mathrm{T}}=0$,

has exactly one positive root $\left[\mathrm{H}^{+}\right]$, for any given value of Alk $\mathrm{k}_{\mathrm{T}}$ the sum of the respective alkalinity contributions over the set $\left\{\mathrm{H}_{n_{i}} \mathrm{~A}_{[i]} \mid i=1, \ldots\right\}$ of all the acid systems active in the sample is a strictly decreasing function of $\left[\mathrm{H}^{+}\right]$; the contribution from the dissociation of water is also strictly decreasing with $\left[\mathrm{H}^{+}\right]$, and may theoretically take any value between $+\infty$ and $-\infty$.

\section{Alkalinity-pH equation in biogeochemical models: approximations and methods of solution}

In this section, we are going to review the most common approximations used in ocean carbon and biogeochemical cycle models, focusing on how the corresponding equation is solved.

\subsection{Carbonate alkalinity based solutions}

The straight approximation $\mathrm{Alk}_{\mathrm{T}} \simeq \mathrm{Alk}_{\mathrm{C}}$ is often used in textbooks (e.g. Broecker and Peng, 1982). There are only a few models (e.g. Opdyke and Walker, 1992; Walker and Opdyke, 1995) that use it directly for their carbonate chemistry speciation. For numerical modelling purposes, its usage is indeed somewhat problematic. $\left[\mathrm{H}^{+}\right]$calculated from $\mathrm{Alk}_{\mathrm{T}}$ and $C_{\mathrm{T}}$ data, by assuming that $\mathrm{Alk}_{\mathrm{C}}=\mathrm{Alk}_{\mathrm{T}}$ are typically $30-40 \%$ too low (i.e. $0.15-0.2 \mathrm{pH}$ units too high) for present-day seawater samples. Furthermore, the sensitivity of the $C_{\mathrm{T}}-\mathrm{Alk}_{\mathrm{C}}$ system to perturbations is stronger than that of the $C_{\mathrm{T}}-\mathrm{Alk}_{\mathrm{CBW}}$ system: equilibrium $p \mathrm{CO}_{2}$ changes, e.g. are of the order of $20 \%$ larger (Munhoven, 1997).

The calculation of $\left[\mathrm{H}^{+}\right]$from $C_{\mathrm{T}}-\mathrm{Alk}_{\mathrm{C}}$ remains nevertheless important, as more advanced methods such as those proposed by Bacastow (1981), Peng et al. (1987) or Follows et al. (2006), where $\mathrm{Alk}_{\mathrm{C}}$ is iteratively recalculated from more complete approximations to $\mathrm{Alk}_{\mathrm{T}}$ (ICAC methods - see below), rely on it.

\subsubsection{Fundamental solution}

For given $\mathrm{Alk}_{\mathrm{C}}$ and $C_{\mathrm{T}}\left(C_{\mathrm{T}}>0\right)$, the equation to solve for $\left[\mathrm{H}^{+}\right]$is

$$
R_{\mathrm{C}}\left(\left[\mathrm{H}^{+}\right]\right) \equiv C_{\mathrm{T}} \frac{K_{1}\left[\mathrm{H}^{+}\right]+2 K_{1} K_{2}}{\left[\mathrm{H}^{+}\right]^{2}+K_{1}\left[\mathrm{H}^{+}\right]+K_{1} K_{2}}-\mathrm{Alk}_{\mathrm{C}}=0 .
$$

Following our discussion in Sect. 2.2.1, Eq. (7) has a positive root if and only if $0<\mathrm{Alk}_{\mathrm{C}}<2 C_{\mathrm{T}}$; if there is a positive root, it is unique.

Equation (7) can be directly solved after conversion to the quadratic equation:

$P_{\mathrm{C}}\left(\left[\mathrm{H}^{+}\right]\right) \equiv\left[\mathrm{H}^{+}\right]^{2}+a_{1}\left[\mathrm{H}^{+}\right]+a_{0}=0$,

where

$a_{1}=K_{1}\left(1-\frac{C_{\mathrm{T}}}{\mathrm{Alk}_{\mathrm{C}}}\right) \quad$ and $\quad a_{0}=K_{1} K_{2}\left(1-\frac{2 C_{\mathrm{T}}}{\mathrm{Alk}_{\mathrm{C}}}\right)$.

For valid $\mathrm{Alk}_{\mathrm{C}}$ values (i.e. for $0<\mathrm{Alk}_{\mathrm{C}}<2 C_{\mathrm{T}}$ ), this quadratic equation has two real roots, a positive and a negative one. The positive root is

$\left[\mathrm{H}^{+}\right]=Q\left(\mathrm{Alk}_{\mathrm{C}}, C_{\mathrm{T}}\right) \equiv \frac{K_{1}}{2}\left(\frac{C_{\mathrm{T}}}{\operatorname{Alk}_{\mathrm{C}}}-1+\sqrt{\Delta_{\mathrm{C}}}\right)$,

where

$\Delta_{\mathrm{C}}=\left(1-\frac{C_{\mathrm{T}}}{\mathrm{Alk}_{\mathrm{C}}}\right)^{2}+4 \frac{K_{2}}{K_{1}}\left(\frac{2 C_{\mathrm{T}}}{\mathrm{Alk}_{\mathrm{C}}}-1\right)$.

For $\mathrm{Alk}_{\mathrm{C}}$ values that are out of range Eq. (8) either has two negative or two complex roots. 


\subsubsection{Alternative methods}

There are other methods to derive $\left[\mathrm{H}^{+}\right]$from $\mathrm{Alk}_{\mathrm{C}}$ and $C_{\mathrm{T}}$. All of them ultimately seem to rely on the formulae of Park (1969) for deriving the complete speciation of the carbonate system directly from $\mathrm{Alk}_{\mathrm{C}}$ and $C_{\mathrm{T}}$, without explicitly using $\left[\mathrm{H}^{+}\right]$. Antoine and Morel (1995) first calculate $\left[\mathrm{CO}_{2}\right]$ from $C_{\mathrm{T}}$ and $\mathrm{Alk}_{\mathrm{C}}$ (which involves the solution of a first parabolic equation), and then derive $\left[\mathrm{H}^{+}\right]$from the relationship $\left[\mathrm{CO}_{2}\right]=\mathrm{Alk}_{\mathrm{C}}\left[\mathrm{H}^{+}\right]^{2} /\left(K_{1}\left[\mathrm{H}^{+}\right]+2 K_{1} K_{2}\right)$, which requires the solution of a second parabolic equation. Ridgwell (2001) first determines the complete speciation of the carbonate system, referring for the adopted procedure to Millero and Sohn (1992), who actually only report the formulae of Park (1969). $\mathrm{He}$ then derives two different estimates for $\left[\mathrm{H}^{+}\right]$, based upon the definitions of the first and second dissociation constants of carbonic acid, and finally uses the geometric mean of these two estimates as a solution for Eq. (7).

There are no obvious advantages for calling upon these methods instead of the direct quadratic solution above. Even if carefully implemented, both require a significantly higher number of operations than the solution outlined above. Those methods offer a direct access to carbonate speciation (at least in part), which can, however, also be calculated at little extra cost from $\left[\mathrm{H}^{+}\right]$.

\subsubsection{Iterative carbonate alkalinity correction methods}

In most common natural settings, the difference between $\mathrm{Alk}_{\mathrm{C}}$ and $\mathrm{Alk} \mathrm{k}_{\mathrm{T}}$, albeit small, leads to significant errors on $\left[\mathrm{H}^{+}\right]$, if $A \mathrm{k}_{\mathrm{T}}$ is used in place of $\mathrm{Alk}_{\mathrm{C}}$ and one of the procedures above is used to calculate it from $C_{\mathrm{T}}$. To overcome this problem, Alk $\mathrm{C}$ can be estimated from Alk $\mathrm{K}_{\mathrm{T}}$, and then iteratively corrected until stabilization occurs. Such a procedure, which we call here iterative carbonate alkalinity correction (ICAC) can a priori be used with arbitrary chemical compositions, provided $\mathrm{Alk}_{\mathrm{C}}$ represents a significant fraction of $\mathrm{Alk}_{\mathrm{T}}$. If $\mathrm{Alk}_{\mathrm{C}}$ makes up only a small fraction of $\mathrm{Alk}_{\mathrm{T}}$, the method is likely to exhibit unstable behaviour.

In the most straightforward ICAC method, one starts from a trial value $H_{0}$ for $\left[\mathrm{H}^{+}\right]$, a first estimate $\mathrm{Alk}_{\mathrm{C}, 0}$ is obtained by subtracting the concentrations of all non-carbonate components from $\mathrm{Alk}_{\mathrm{T}}$. That $\mathrm{Alk}_{\mathrm{C}, 0}$ is then used to calculate a new (improved) estimate $H_{1}$ for $\left[\mathrm{H}^{+}\right]$from Eqs. (9) and (10) or one of the alternative methods. $H_{1}$ is then used to calculate a new estimate $\mathrm{Alk}_{\mathrm{C}, 1}$ from $\mathrm{Alk}_{\mathrm{T}}$ as above and the procedure is iterated until some predefined convergence criterion is fulfilled. This procedure is a classical fixed-point iteration:

$$
H_{n+1}=Q\left(\mathrm{Alk}_{\mathrm{C}}\left(\mathrm{Alk}_{\mathrm{T}}, H_{n}\right), C_{\mathrm{T}}\right) .
$$

In this recurrence, $\mathrm{Alk}_{\mathrm{C}}\left(\mathrm{Alk}_{\mathrm{T}}, H_{n}\right)$ is the estimate of $\mathrm{Alk}_{\mathrm{C}}$ obtained from $\mathrm{Alk}_{\mathrm{T}}$ by subtracting all the non-carbonate components estimated by using $H_{n}$. Pure fixed-point iterative schemes may be prone to convergence problems (slow convergence or no convergence at all). If the procedure is convergent, the rate of convergence is linear.

This plain fixed-point-iteration ICAC method was recently made popular again by Follows et al. (2006). These authors argue that in carbon cycle model simulation experiments, where there is little change in $\mathrm{pH}$ from one time step to the next, a single iteration may already provide a sufficiently accurate estimate of $\left[\mathrm{H}^{+}\right]$to derive acceptable $p \mathrm{CO}_{2}$ estimates, for any chosen approximation of total alkalinity. Follows et al. (2006) suggest, if necessary, to repeat the fixedpoint iteration until a sufficiently accurate estimate is found.

There are a number of models that rely on the ICAC approach for their pH determination. Peng et al. (1987) consider Alk $\mathrm{K}_{\mathrm{CBW}}$ plus the contributions from silicic and phosphoric acid systems in their representation of total alkalinity. ${ }^{1}$ They use an initial value of $10^{-8}$ and stop their iterations once $|(\Delta H) / H|<0.005 \%$. They report that less than ten iterations are generally sufficient. Antoine and Morel (1995) adopt $\mathrm{Alk}_{\mathrm{CBW}}$ as an approximation to $\mathrm{Alk}_{\mathrm{T}}$. At each step, they derive $\left[\mathrm{H}^{+}\right]$from $C_{\mathrm{T}}$ and $\mathrm{Alk}_{\mathrm{C}}$ by using their special procedure described above. They iterate until two successive $\mathrm{Alk}_{\mathrm{C}}$ estimates differ by less than $10^{-8}$ (no units given). Ridgwell (2001) adopts Alk $\mathrm{CB}+\left[\mathrm{OH}^{-}\right]+1.1\left[\mathrm{PO}_{4}^{3-}\right]$ as an approximation to total alkalinity. He calculates $\left[\mathrm{H}^{+}\right]$at each step from $C_{\mathrm{T}}$ and $\mathrm{Alk}_{\mathrm{C}}$ by using his own procedure described above. GENIE (Ridgwell et al., 2007) initially used the same procedure as Ridgwell (2001); in more recent versions of GENIE, a complete representation of the phosphoric acid component is used (A. Ridgwell, personal communication, 2012). Arndt et al. (2011) use $\mathrm{Alk}_{\mathrm{CBW}}+\left[\mathrm{HS}^{-}\right]$as an approximation to total alkalinity in GEOCLIM reloaded. They continue to iterate until $\left|\mathrm{Alk}_{\mathrm{CBW}}+\left[\mathrm{HS}^{-}\right]-\mathrm{Alk}_{\mathrm{T}}\right|<10^{-6}$ (no units given). The method is further used in LOVECLIM (A. Mouchet, personal communication, 2012) with $\mathrm{Alk}_{\mathrm{CBW}}$ as an approximation for total alkalinity (Goosse et al., 2010) and most probably still in some others that, unfortunately, do not provide details about the calculation procedures adopted.

Bacastow (1981) proposed a variant to improve the rate of convergence of fixed-point iterations. That variant only uses the recurrence described above for the first two iterates. From the third iteration on, Bacastow (1981) switches to a secant method to solve the fixed-point equation $H-$ $Q\left(\mathrm{Alk}_{\mathrm{C}}\left(\mathrm{Alk}_{\mathrm{T}}, H\right)\right)=0 .^{2}$ Fixed-point iterations are thus only used to provide starting values for the solution of the fixedpoint equation by the secant method. The rate of convergence of the method is strongly increased by this approach (and the

\footnotetext{
${ }^{1}$ Peng et al. (1987) adopt, however, a slightly different definition of total alkalinity by systematically weighting species by their respective charge. This leads to differences with the phosphoric acid system: e.g. the definition of Peng et al. (1987) is equivalent to adopting $m=0$ for the phosphoric acid system.

${ }^{2}$ Bacastow (1981) actually solves the alkalinity equation for the scaled inverse of $\left[\mathrm{H}^{+}\right]$. We provide codes for the two approaches, although we only base our discussions on the version with secant iterations on $\left[\mathrm{H}^{+}\right]$.
} 
domain of convergence slightly enlarged - see numerical experiments below). However, for some $C_{\mathrm{T}}-\mathrm{Alk}_{\mathrm{T}}$ combinations the underlying fixed-point equation may still give rise to convergence problems, even with the secant method. However as will be shown below, the method of Bacastow (1981) is strongly preferable over the pure fixed-point scheme.

The Hadley Centre Ocean Carbon Cycle (HadOCC) model (Palmer and Totterdell, 2001) uses Bacastow's method for its carbonate speciation calculation, with the $\mathrm{Alk}_{\mathrm{CBW}}$ approximation.

\subsection{Carbonate and borate alkalinity based solution}

Only a few models appear to use $\mathrm{pH}$ calculation routines based upon Alk $\mathrm{CB}_{\mathrm{CB}}$. MBM-MEDUSA (Munhoven and François, 1996; Munhoven, 1997, 2007) is one of them, the model of Marchal et al. (1998) is another one.

\subsubsection{Basic formulation and solution methods}

The equation to solve for $\left[\mathrm{H}^{+}\right]$is, for given $\mathrm{Alk}_{\mathrm{CB}}, C_{\mathrm{T}}$ and $B_{\mathrm{T}}$,

$$
\begin{aligned}
R_{\mathrm{CB}}\left(\left[\mathrm{H}^{+}\right]\right) \equiv & C_{\mathrm{T}} \frac{K_{1}\left[\mathrm{H}^{+}\right]+2 K_{1} K_{2}}{\left[\mathrm{H}^{+}\right]^{2}+K_{1}\left[\mathrm{H}^{+}\right]+K_{1} K_{2}} \\
& +B_{\mathrm{T}} \frac{K_{\mathrm{B}}}{\left[\mathrm{H}^{+}\right]+K_{\mathrm{B}}}-\mathrm{Alk}_{\mathrm{CB}} \\
= & 0 .
\end{aligned}
$$

This equation may be converted into the polynomial equation:

$$
P_{\mathrm{CB}}\left(\left[\mathrm{H}^{+}\right]\right) \equiv\left[\mathrm{H}^{+}\right]^{3}+c_{2}\left[\mathrm{H}^{+}\right]^{2}+c_{1}\left[\mathrm{H}^{+}\right]+c_{0}=0,
$$

with

$c_{2}=K_{\mathrm{B}}\left(1-\frac{B_{\mathrm{T}}}{\mathrm{Alk}_{\mathrm{CB}}}\right)+K_{1}\left(1-\frac{C_{\mathrm{T}}}{\mathrm{Alk}_{\mathrm{CB}}}\right)$,

$c_{1}=K_{1}\left(K_{\mathrm{B}}\left(1-\frac{B_{\mathrm{T}}}{\mathrm{Alk}_{\mathrm{CB}}}-\frac{C_{\mathrm{T}}}{\mathrm{Alk}_{\mathrm{CB}}}\right)+K_{2}\left(1-2 \frac{C_{\mathrm{T}}}{\mathrm{Alk}_{\mathrm{CB}}}\right)\right)$,

$c_{0}=K_{1} K_{2} K_{\mathrm{B}}\left(1-\frac{2 C_{\mathrm{T}}+B_{\mathrm{T}}}{\mathrm{Alk}_{\mathrm{CB}}}\right)$.

Following our discussion in Sect. 2.2.2, Eq. (12) has a positive root if and only if $0<\mathrm{Alk}_{\mathrm{CB}}<2 C_{\mathrm{T}}+B_{\mathrm{T}}$; if there is a positive root, it is unique. The same holds for the cubic Eq. (13).

The cubic equation could possibly be solved with closed formulae, such as Cardano's formulae (which may, however, suffer from precision problems, require numerically expensive cubic root evaluations or possibly complex arithmetic) or Viète's trigonometric formulae (which require a combination of an arccosine, a cosine and a square root). When adopted, the cubic Eq. (13) is therefore generally solved numerically with a Newton-Raphson scheme. In this case, determining an adequate starting value is the main problem to address in order to design a robust and fast solution algorithm.

\subsubsection{Efficient starting value for iterative methods}

An excellent initial value for the Newton-Raphson scheme can be found by adopting the following procedure:

1. locate the local minimum closest to the largest root - if it exists, it is the extremum;

2. develop $P_{\mathrm{CB}}\left(\left[\mathrm{H}^{+}\right]\right)$to second order around that minimum; and

3. determine the greatest root of the resulting parabola and use it as a starting value.

That local minimum, if it exists (i.e. if $c_{2}^{2}-3 c_{1}>0$ ), is located at

$H_{\min }=\frac{-c_{2}+\sqrt{c_{2}^{2}-3 c_{1}}}{3}=\frac{-c_{1}}{c_{2}+\sqrt{c_{2}^{2}-3 c_{1}}}$.

The Taylor expansion to second order in $H_{\min }$, thus intersects the $H$ axis on the right-hand side of $H_{\min }$ at

$$
H_{0}=H_{\min }+\sqrt{-\frac{P_{\mathrm{CB}}\left(H_{\min }\right)}{\sqrt{c_{2}^{2}-3 c_{1}}}},
$$

provided $P_{\mathrm{CB}}\left(H_{\min }\right)<0$. By completing the Taylor expansion to third order, it is straightforward to show that $H_{0}$ is greater than the root.

The so-defined $H_{0}$ provides an excellent starting value not only for solving the cubic polynomial equation, but also for other iterative methods.

\subsection{Carbonate, borate and water self-ionization alkalinity}

With Alk $\mathrm{CBW}_{\mathrm{T}}, C_{\mathrm{T}}$ and $B_{\mathrm{T}}$ given, the equation to solve is

$$
\begin{aligned}
& R_{\mathrm{CBW}}\left(\left[\mathrm{H}^{+}\right]\right) \\
& \equiv C_{\mathrm{T}} \frac{K_{1}\left[\mathrm{H}^{+}\right]+2 K_{1} K_{2}}{\left[\mathrm{H}^{+}\right]^{2}+K_{1}\left[\mathrm{H}^{+}\right]+K_{1} K_{2}}+B_{\mathrm{T}} \frac{K_{\mathrm{B}}}{\left[\mathrm{H}^{+}\right]+K_{\mathrm{B}}} \\
& \quad+\frac{K_{\mathrm{W}}}{\left[\mathrm{H}^{+}\right]}-\left[\mathrm{H}^{+}\right]-\mathrm{Alk}_{\mathrm{CBW}}=0 .
\end{aligned}
$$

One may either solve this equation in that rational fraction form with some iterative root-finding method or by one of the ICAC methods described above, or one may transform it into a quintic polynomial equation:

$$
\begin{aligned}
& P_{\mathrm{CBW}}\left(\left[\mathrm{H}^{+}\right]\right) \\
& \equiv\left[\mathrm{H}^{+}\right]^{5}+q_{4}\left[\mathrm{H}^{+}\right]^{4}+q_{3}\left[\mathrm{H}^{+}\right]^{3}+q_{2}\left[\mathrm{H}^{+}\right]^{2}+q_{1}\left[\mathrm{H}^{+}\right]+q_{0} \\
& =0
\end{aligned}
$$


with

$$
\begin{aligned}
q_{4}= & \mathrm{Alk}_{\mathrm{CBW}}+K_{1}+K_{\mathrm{B}}, \\
q_{3}= & \left(\mathrm{Alk}_{\mathrm{CBW}}-C_{\mathrm{T}}+K_{\mathrm{B}}\right) K_{1} \\
& +\left(\mathrm{Alk}_{\mathrm{CBW}}-B_{\mathrm{T}}\right) K_{\mathrm{B}}+K_{1} K_{2}-K_{\mathrm{W}}, \\
q_{2}= & \left(\mathrm{Alk}_{\mathrm{CBW}}-2 C_{\mathrm{T}}+K_{\mathrm{B}}\right) K_{1} K_{2} \\
& +\left(\mathrm{Alk}_{\mathrm{CBW}}-C_{\mathrm{T}}-B_{\mathrm{T}}\right) K_{1} K_{\mathrm{B}}-K_{1} K_{\mathrm{W}}-K_{\mathrm{B}} K_{\mathrm{W}}, \\
q_{1}= & \left(\mathrm{Alk}_{\mathrm{CBW}}-2 C_{\mathrm{T}}-B_{\mathrm{T}}\right) K_{1} K_{2} K_{\mathrm{B}} \\
& -K_{1} K_{2} K_{\mathrm{W}}-K_{1} K_{\mathrm{B}} K_{\mathrm{W}}, \\
q_{0}= & -K_{1} K_{2} K_{\mathrm{B}} K_{\mathrm{W}} .
\end{aligned}
$$

The polynomial equation can then be solved with appropriate standard root finding techniques, selecting the positive root found. Equations (15) and (14) have the same unique positive root: when Eq. (14) is multiplied by the product of all the denominators of the fractions included - a product that does not change sign for $\left[\mathrm{H}^{+}\right]>0-$ to transform it into Eq. (15) no new sign changes can be obtained for $\left[\mathrm{H}^{+}\right]>0$.

Alk $\mathrm{CBW}_{\mathrm{CB}}$ is probably the most commonly used approximation for total alkalinity in global carbon cycle models of all kinds of complexity. It was already adopted by Bacastow and Keeling (1973), who based their $\mathrm{pH}$ calculation on the quintic Eq. (15), which they solve by Newton's method, with a stopping criterion $|(\Delta H) / H|<10^{-10}$. Hoffert et al. (1979) adopt the same procedure (for which they refer to Keeling, 1973 and Bacastow and Keeling, 1973), but with a less stringent stopping criterion $|(\Delta H) / H|<10^{-6}$. Keeling (1973) uses a variant, where $C_{\mathrm{T}}$ is replaced by an equivalent term in $p \mathrm{CO}_{2}$.

As already mentioned above, LOVECLIM (Goosse et al., 2010) and HadOCC (Palmer and Totterdell, 2001) use $\mathrm{Alk}_{\mathrm{CBW}}$ as an approximation for total alkalinity. Alk $\mathrm{CBW}_{\mathrm{CB}}$ is also used in the PISCES model (Aumont and Bopp, 2006), following a simplified version of the OCMIP standard protocol (see next section). PISCES is included in NEMO and in some versions of the Bern3D model (Gangst $\varnothing$ et al., 2011). Other models that base their $\mathrm{pH}$ calculation on $\mathrm{Alk}_{\mathrm{CBW}}$ include the Hamburg Model of the Ocean Carbon Cycle (HaMOCC) family (Maier-Reimer and Hasselmann, 1987; Heinze et al., 1991; Maier-Reimer, 1993; Maier-Reimer et al., 2005), the models of Bolin et al. (1983) and Shaffer et al. (2008). No details regarding the adopted solution algorithms are provided, though.

\subsection{More complete approximations: rational function based solvers}

When additional components in total alkalinity need to be considered besides carbonate, borate and water selfionization, converting the resulting rational function equation to an equivalent polynomial form becomes more and more tedious and the rational function form becomes the preferred basis for finding the solution. ICAC methods are the only ones that we have encountered so far that could pos- sibly be used to address this problem. However, they bear some potential pitfalls: despite having a solution, the underlying fixed-point equation may be difficult to solve numerically; intermediate estimates of $\mathrm{Alk}_{\mathrm{C}}$ may go out of bounds (remember that $\mathrm{Alk}_{\mathrm{C}}$ may only take values between 0 and $2 C_{\mathrm{T}}$ ). ICAC methods can therefore not be guaranteed to find the solution.

The only commonly used carbonate chemistry routine that directly solves the rational function form of the equation is that from the Ocean Carbon Cycle Model Intercomparison Project (OCMIP). For the purpose of that project, Orr et al. (2000) prepared standard carbonate speciation routines. Total alkalinity is approximated by $\mathrm{Alk}_{\mathrm{T}} \simeq\left[\mathrm{HCO}_{3}^{-}\right]+$ $2 \times\left[\mathrm{CO}_{3}^{2-}\right]+\left[\mathrm{B}(\mathrm{OH})_{4}^{-}\right]+\left[\mathrm{OH}^{-}\right]+\left[\mathrm{HPO}_{4}^{2-}\right]+2 \times\left[\mathrm{PO}_{4}^{3-}\right]+$ $\left[\mathrm{H}_{3} \mathrm{SiO}_{4}^{-}\right]-\left[\mathrm{H}^{+}\right]_{\mathrm{f}}-\left[\mathrm{HSO}_{4}^{-}\right]-[\mathrm{HF}]-\left[\mathrm{H}_{3} \mathrm{PO}_{4}\right]$. The different species concentrations were, as above, expressed as a function of the total concentrations of their respective acid systems and of $\left[\mathrm{H}^{+}\right]$. The resulting equation was then solved for $\mathrm{pH}$ by a hybrid Newton-bisection method, based upon the rtsafe solver from Press et al. (1989). All of the models that participated in OCMIP had to use the provided routines for a set of well defined experiments. A number of models still routinely use these OCMIP routines for their $\mathrm{pH}$ calculations. These include some versions of the Bern3D model (Müller et al., 2008) and the NCAR global coupled carbon cycle-climate model CSM1.4-carbon (Doney et al., 2006). As mentioned above, PISCES (Aumont and Bopp, 2006) includes a version of the OCMIP solver trimmed down to $\mathrm{Alk}_{\mathrm{CBW}}$ only. Other models still offer the OCMIP solvers as an option.

\subsection{Other approaches}

Luff et al. (2001) have provided a suite of $\mathrm{pH}$ calculation routines mainly meant to be used in reactive transport models, but suitable for general speciation calculations as well. The methods proposed by Luff et al. (2001) solve the complete system of equations that control the chemical equilibria between the individual species considered in the total alkalinity approximation. These are required for grid-based reactive transport models where different species are diffusing at different diffusivities. For common applications in biogeochemical carbon cycle models, this approach is nevertheless unnecessarily complex.

There are still some other fine $\mathrm{pH}$ solvers, such as CO2SYS of Lewis and Wallace (1998) and derivatives (spreadsheet versions, MATLAB versions, etc. - see http: //cdiac.ornl.gov/oceans/co2rprt.html for more information), the MATLAB routines from Zeebe and Wolf-Gladrow (2001), or the R packages seacarb (Lavigne and Gattuso, 2012) and AquaEnv (Hofmann et al., 2010, 2012). These are, however, generally not suitable for inclusion in global biogeochemical models, as they were developed with special programming environments in mind. Their focus is more on data processing or modelling with the special programming 
environment they were designed for. As their names already suggest, they are mainly aimed at carbonate speciation calculations. They also often offer the possibility to chose any two among $\mathrm{pH},\left[\mathrm{CO}_{2}\right]\left(\right.$ or $\left.p \mathrm{CO}_{2}\right),\left[\mathrm{HCO}_{3}^{-}\right],\left[\mathrm{CO}_{2}^{2-}\right], C_{\mathrm{T}}$, or $\mathrm{Alk}_{\mathrm{T}}$ to calculate all the others.

\section{4 pH-scale considerations}

As shortly mentioned above, there are a few subtleties related to $\mathrm{pH}$ scales that still need to be clarified. The mere existence of more than one $\mathrm{pH}$ scale reflects the difficulties to apply the fundamental definition of $\mathrm{pH}$ (which involves an immeasurable quantity - see next section) to the experimental determination of acidity in seawater. All of our calculations nevertheless rely on the availability of equilibrium constants that have to be experimentally derived and we therefore have to care about differences arising from the usage of various $\mathrm{pH}$ scales.

Let us, similarly to Bates and Culberson (1977) consider the equilibrium relationship (the mass action law) for an acid dissociation reaction. Without loss of generality, we may write that relationship for the first dissociation reaction of our generic acid from Sect. 2.2.4:

$K_{1}=\frac{\left[\mathrm{H}^{+}\right]\left[\mathrm{H}_{n-1} \mathrm{~A}^{-}\right]}{\left[\mathrm{H}_{n} \mathrm{~A}\right]}$.

When the dependency of $K_{1}$ on temperature and salinity is experimentally determined, the fraction $\left[\mathrm{H}_{n-1} \mathrm{~A}^{-}\right] /\left[\mathrm{H}_{n} \mathrm{~A}\right]$ is measured or calculated for each experiment. $\left[\mathrm{H}^{+}\right]$cannot be directly measured, but gets assigned a value from some $\mathrm{pH}$ measurement via the reverse relationship $\left[\mathrm{H}^{+}\right]=10^{-\mathrm{pH}}$. Taking the negative logarithm (antilogarithm) of the previous equation and writing $p K_{1}=-\log K_{1}$, we get

$p K_{1}=\mathrm{pH}-\log \left(\frac{\left[\mathrm{H}_{n-1} \mathrm{~A}^{-}\right]}{\left[\mathrm{H}_{n} \mathrm{~A}\right]}\right)$.

In a given setting (i.e. for given temperature, salinity, pressure, solution chemistry, etc.), the ratio $\left[\mathrm{H}_{n-1} \mathrm{~A}^{-}\right] /\left[\mathrm{H}_{n} \mathrm{~A}\right]$ is set and different calibrations of the $\mathrm{pH}$-meter used, i.e. different scales chosen for the $\mathrm{pH}$-meter, will thus produce different $p K_{1}$ values. Any experimentally derived parameterization for $K_{1}$ can therefore only be used in conjunction with $\mathrm{a} \mathrm{H}^{+}$concentration scale that is consistent with the $\mathrm{pH}$ scale that was used to derive it. Before a particular empirical parameterization for $K_{1}$ can be used with a different scale of $\mathrm{pH}$ (e.g. due to a different conventional or operational definition of $\mathrm{pH}$ ), it must be converted.

Additional conversion may be required because of the usage of different concentration units: both molal units $\left(\mathrm{mol} / \mathrm{kg}-\mathrm{H}_{2} \mathrm{O}\right)$ and $\mathrm{mol} / \mathrm{kg}$-seawater are common. They can be converted according to $[\mathrm{mol} / \mathrm{kg}-\mathrm{SW}]=$ $m\left(\mathrm{~mol} / \mathrm{kg}-\mathrm{H}_{2} \mathrm{O}\right) \times(1-0.001005 \mathrm{~S})$ (Dickson et al., 2007, chapter 5 , p. 13), where $S$ denotes salinity. For $S=35$, the difference between the values is about $\pm 3.5 \%$; in log units, the values differ by \pm 0.016 .

There is abundant literature on $\mathrm{pH}$ scales for seawater. Besides the original fundamental papers by, e.g. Hansson (1973), Bates and Culberson (1977), Khoo et al. (1977), Dickson and Riley (1979), Bates (1982) or Dickson (1990), the classical review papers by Dickson $(1984,1993)$, or standard textbooks (e.g. Zeebe and Wolf-Gladrow, 2001), there are also several recent papers on the subject, such as the reviews by Dickson (2010) and Marion et al. (2011) or the research paper by Waters and Millero (2013). In the following sections, we will therefore only give a comparatively general overview, which we have nevertheless tried to keep as selfconsistent as possible.

\subsection{Fundamental definition of $\mathrm{pH}$ and standard potentiometric determination of $\mathrm{pH}$}

While $\mathrm{pH}$ as a measure of the acidity of a solution may appear as a straightforward concept, its experimental determination and interpretation are not. The fundamental definition of $\mathrm{pH}$ recommended by the International Union of Pure and Applied Chemistry (IUPAC, Buck et al., 2002) states that $\mathrm{pH}=-\log \left(a_{\mathrm{H}^{+}}\right)$, where $a_{\mathrm{H}^{+}}$denotes the activity of the $\mathrm{H}^{+}$ions in solution. $a_{\mathrm{H}^{+}}$is related to the concentration of $\mathrm{H}^{+}$through the activity coefficient $\gamma_{\mathrm{H}^{+}}$, such that $a_{\mathrm{H}^{+}}=\gamma_{\mathrm{H}^{+}}\left[\mathrm{H}^{+}\right]$. The activity coefficient of $\mathrm{H}^{+}$depends on the exact chemical composition of the solution. The more dilute the solution is, the closer the values of activity coefficients come to one. The activity of an individual ion in solution cannot be measured by any thermodynamically valid method and the measurement of $\mathrm{pH}$ therefore requires an operational convention (Buck et al., 2002). The reasons for the existence of several $\mathrm{pH}$ scales in seawater then also simply "[...] reflect the gradual gradual refinement of the experimentally convenient potentiometric determination of acidity in order that the numbers obtained might be usefully interpreted as a property of hydrogen ion in solution" (Dickson, 1984).

The potentiometric method mentioned by Dickson (1984) is the classical method used for the quantitative determination of acidity in an aqueous solution. It is based upon the use of electrochemical cells and has been used for more than 100 yr. Potentiometric $\mathrm{pH}$ measuring devices for practical use are made up by two electrodes: an $\mathrm{H}^{+}$sensitive glasselectrode and a well reproducible second electrode, a socalled reference electrode. Both electrodes are immersed into the sample solution to form an electrochemical cell. The potential difference between the two electrodes, i.e. the emf (electromotive force) of the cell, is linked to the logarithm of the activity of the $\mathrm{H}^{+}$ions in solution. The total emf of the cell, $E$, can be separated into three major contributions (Dickson, 1984). The first one, which we denote here as $E_{\text {gem }}$, is due to the potential difference across the membrane of the glass electrode, which is assumed to behave following 
Nernst's law, i.e.

$E_{\text {gem }}=(R T \ln 10 / F) \log \left(a_{\mathrm{H}^{+}}\right)$,

where $R$ is the universal gas constant, $T$ the absolute temperature and $F$ Faraday's constant. The second contribution, $E_{\mathrm{J}}$, is due to the potential difference across the liquid junction that is required to bring the filling solution of the reference electrode into contact with the sample solution. The third one, $E^{\circ \prime}$, takes into account all of the other potential differences arising from the characteristics of the internal electrolytes and the design of the two cells, and it can be assumed that this is an invariant of the instrument. The measured emf is thus such that

$$
E=R T \ln 10 / F \log \left(a_{\mathrm{H}^{+}}\right)+E_{\mathrm{J}}+E^{\circ \prime} .
$$

By using this cell for sequentially measuring the emf of the standard buffer solution $\mathrm{S}, E_{\mathrm{S}}$, and of the sample solution X, $E_{\mathrm{X}}$, (both at the same temperature $T$ ) we have

$\log \left(a_{\mathrm{H}^{+}}(\mathrm{X})\right)=\log \left(a_{\mathrm{H}^{+}}(\mathrm{S})\right)+\frac{E_{\mathrm{S}}-E_{\mathrm{X}}}{R T \ln 10 / F}+\frac{E_{\mathrm{JX}}-E_{\mathrm{JS}}}{R T \ln 10 / F}$.

This property is used (Buck et al., 2002) to operationally define the $\mathrm{pH}$ of the sample $\mathrm{X}$ from its deviation from the known or assigned $\mathrm{pH}$ of the standard buffer solution $\mathrm{S}$, as

$\mathrm{pH}(\mathrm{X})=\mathrm{pH}(\mathrm{S})+\frac{E_{\mathrm{S}}-E_{\mathrm{X}}}{R T \ln 10 / F}$,

thus implicitly assuming that the residual liquid junction potential $E_{\mathrm{JX}}-E_{\mathrm{JS}}$ can be neglected. Buck et al. (2002) propose a number of primary standards (buffer solutions) that have to meet some fundamental metrological qualities. These primary standards are commonly known as NBS buffers (where NBS stands for the US National Bureau of Standards, now National Institute of Standards and Technology, NIST). One of the constraints imposed upon these standards is that their ionic strengths must not exceed 0.1 molal: the calibration procedure of the standards rests to some extent on the Debye-Hückel theory for ionic interactions, which is applicable only for ionic strengths $<0.1$ molal (Buck et al., 2002).

\subsection{Complications and simplifications for seawater $\mathrm{pH}$}

Seawater has a much higher ionic strength of 0.7 molal (for $S=35$ ) than the standard NBS buffers. The use of such dilute buffers for the determination of $\mathrm{pH}$ in seawater samples is therefore problematic: the concentration gradients across the reference electrode's liquid junction will be significantly different between any seawater sample and the standard buffers.

Hansson (1973) therefore developed and calibrated buffers on the basis of artificial seawater. In addition to this, Hansson (1973) also devised new pH scales for seawater. His scales are based upon the peculiar composition of natural seawater. Of all the solutes present, six alone make up 99.3\% of the total dissolved salts: $\mathrm{Cl}^{-} 55.0 \%, \mathrm{Na}^{+} 30.7 \%, \mathrm{SO}_{4}^{2-}$ $7.7 \%, \mathrm{Mg}^{2+} 3.6 \%, \mathrm{Ca}^{2+} 1.2 \%$ and $\mathrm{K}^{+} 1.1 \%$ (Millero et al., 2008); and their respective ratios remain essentially constant throughout the oceans. All of the minor constituents, which include carbonate, bicarbonate, all the nutrient salts, $\mathrm{H}^{+}$itself, etc., make up less than $0.7 \%$. Basically, natural seawater can thus be seen as a dilute solution of the minor constituents in a solvent that is an ionic medium of rather high ionic strength, but of constant composition for a given salinity, instead of a concentrated solution of all the solutes in the pure water solvent.

As a result, the activity coefficient of $\mathrm{H}^{+}$remains fairly constant over a large concentration range (and even close to one, since the solution is dilute with the ionic medium as the solvent, Hansson, 1973). Accordingly, the concentrations and activities of $\mathrm{H}^{+}$become equivalent and it is possible to define special $\mathrm{pH}$ scales for seawater that are directly expressed in terms of concentrations. Solutions of well-known concentrations of $\mathrm{H}^{+}$can then easily be used as standard buffer solutions.

\subsection{Towards the definition of seawater $\mathrm{pH}$ scales}

Similarly to dilute aqueous solutions, where it is impossible to distinguish between the free and the different hydrated forms of dissolved $\mathrm{H}^{+}$since water activity is not noticeably changed during experiments, in ionic solutions where the activities of medium ions are constant, it is not possible to distinguish between the free or hydrated $\mathrm{H}^{+}$ions and those formed by protonation of medium ions (Hansson, 1973). In the seawater, $\mathrm{H}^{+}$ions may interact with $\mathrm{SO}_{4}^{2-}$ and, to a lesser extent, $\mathrm{F}^{-}$ions, both of which are present in the solvent ionic medium:

$$
\begin{aligned}
\mathrm{H}^{+}+\mathrm{SO}_{4}^{2-} & \rightleftharpoons \mathrm{HSO}_{4}^{-}, \\
\mathrm{H}^{+}+\mathrm{F}^{-} & \rightleftharpoons \mathrm{HF} .
\end{aligned}
$$

Accordingly, Hansson (1973) defined his pH scales for seawater on the basis of the total analytical concentration of $\mathrm{H}^{+}$in the synthetic seawater buffer solutions, with $\mathrm{pH}_{s}=-\log \left(\left[\mathrm{H}^{+}\right]_{\mathrm{SWS}(\text { Hansson) }}\right)$ where $\left[\mathrm{H}^{+}\right]_{\mathrm{SWS} \text { (Hansson) }}$ is set equal to $\left[\mathrm{H}^{+}\right]_{\mathrm{f}}+\left[\mathrm{HSO}_{4}^{-}\right]+[\mathrm{HF}]$ or to $\left[\mathrm{H}^{+}\right]_{\mathrm{f}}+\left[\mathrm{HSO}_{4}^{-}\right]$, depending on whether the artificial seawater recipe used to prepare the buffer solution includes fluoride or not.

If we denote by

$$
K_{\mathrm{HSO}_{4}(\mathrm{f})}=\frac{\left[\mathrm{H}^{+}\right]_{\mathrm{f}}\left[\mathrm{SO}_{4}^{2-}\right]}{\left[\mathrm{HSO}_{4}^{-}\right]}
$$

and

$$
K_{\mathrm{HF}(\mathrm{f})}=\frac{\left[\mathrm{H}^{+}\right]_{\mathrm{f}}\left[\mathrm{F}^{-}\right]}{[\mathrm{HF}]}
$$

the dissociation constants of $\mathrm{HSO}_{4}^{-}$and $\mathrm{HF}$ on the free hydrogen ion concentration scale, and furthermore by $S_{\mathrm{T}}$ and 
$F_{\mathrm{T}}$ the total sulphate and fluoride concentrations (which are constant for a given salinity), then we find that

$$
\begin{aligned}
& {\left[\mathrm{H}^{+}\right]_{\mathrm{SWS}(\text { Hansson) }}} \\
& =\left[\mathrm{H}^{+}\right]_{\mathrm{f}}\left(1+\frac{S_{\mathrm{T}}}{K_{\mathrm{HSO}_{4}(\mathrm{f})}+\left[\mathrm{H}^{+}\right]_{\mathrm{f}}}+\frac{F_{\mathrm{T}}}{K_{\mathrm{HF}(\mathrm{f})}+\left[\mathrm{H}^{+}\right]_{\mathrm{f}}}\right) .
\end{aligned}
$$

In order to make $\left[\mathrm{H}^{+}\right]_{\mathrm{SWS}}$ strictly proportional to $\left[\mathrm{H}^{+}\right]_{\mathrm{f}}$, Dickson and Riley (1979) slightly modified Hansson's (1973) original definition, thereby simplifying the conversions between different scales and leading to the currently adopted definitions of the three most important $\mathrm{pH}$ scales in seawater (given here with their current common denominations and notations): the free scale $\left(\mathrm{pH}_{\mathrm{f}}=-\log \left(\left[\mathrm{H}^{+}\right]_{\mathrm{f}}\right)\right)$, the total scale $\left(\mathrm{pH}_{\mathrm{T}}=-\log \left(\left[\mathrm{H}^{+}\right]_{\mathrm{T}}\right)\right)$ and the seawater scale $\left(\mathrm{pH}_{\mathrm{SWS}}=-\log \left(\left[\mathrm{H}^{+}\right]_{\mathrm{SWS}}\right)\right)$, where

$$
\begin{aligned}
& {\left[\mathrm{H}^{+}\right]_{\mathrm{T}}=\left[\mathrm{H}^{+}\right]_{\mathrm{f}}\left(1+S_{\mathrm{T}} / K_{\mathrm{HSO}_{4}(\mathrm{f})}\right),} \\
& {\left[\mathrm{H}^{+}\right]_{\mathrm{SWS}}=\left[\mathrm{H}^{+}\right]_{\mathrm{f}}\left(1+S_{\mathrm{T}} / K_{\mathrm{HSO}_{4}(\mathrm{f})}+F_{\mathrm{T}} / K_{\mathrm{HF}(\mathrm{f})}\right) .}
\end{aligned}
$$

While the differences between $\left[\mathrm{H}^{+}\right]_{\text {Sws }}$ and

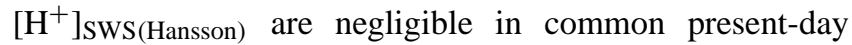
seawater (Munhoven, 1997; Dickson, 2010), those between $\mathrm{pH}_{\mathrm{f}}$ and $\mathrm{pH}_{\mathrm{T}}$ or $\mathrm{pH}_{\mathrm{SWS}}$ are not. At $S=35$ and $T=298.15 \mathrm{~K}$ $\mathrm{pH}_{\mathrm{T}}$ and $\mathrm{pH}_{\mathrm{SWS}}$ are respectively about 0.11 and 0.12 lower than $\mathrm{pH}_{\mathrm{f}}$ (Zeebe and Wolf-Gladrow, 2001), leading to differences of the order of $30 \%$ between the corresponding concentrations of $\mathrm{H}^{+}$.

\subsection{Implications for the alkalinity-pH equations}

In all of the alkalinity-pH equations and equilibrium relationships from Sects. 2 and 3, as well as in the general form of the total alkalinity-pH below, Eq. (21), $\left[\mathrm{H}^{+}\right]$may be expressed on any chosen $\mathrm{pH}$ scale (free, total, seawater) as long as all of the stoichiometric constants $K_{\mathrm{A}_{[i]} 1}, \ldots, K_{\mathrm{A}_{[i]} n_{i}}$ for all of the acid systems are expressed on this same $\mathrm{pH}$ scale. The same holds for $\left[\mathrm{H}^{+}\right]_{\mathrm{f}}$, the free concentration of $\mathrm{H}^{+}$, which must also be expressed on (or converted to) this same scale. According to Eqs. (18) and (19) $\left[\mathrm{H}^{+}\right]_{\mathrm{f}}$ can be expressed as a simple function of the adequate $\left[\mathrm{H}^{+}\right]$:

$\left[\mathrm{H}^{+}\right]_{\mathrm{f}}=\frac{\left[\mathrm{H}^{+}\right]}{s}$,

where $\left[\mathrm{H}^{+}\right]$is one of $\left[\mathrm{H}^{+}\right]_{\mathrm{T}}$ or $\left[\mathrm{H}^{+}\right]_{\mathrm{SWS}}$ and $s$ is the corresponding scale conversion factor derived from either Eq. (18) or (19). Notice that $s \geq 1$ and that $s$ is independent of $\left[\mathrm{H}^{+}\right]$.

Although the differences between $\left[\mathrm{H}^{+}\right]_{\text {SwS }}$ and $\left[\mathrm{H}^{+}\right]_{\text {SWS(Hansson) }}$ are negligible in present-day seawater (and even in acidified seawater as long as $\mathrm{pH}_{\mathrm{SWS}}>5$ ), we are not adopting the approximation $\left[\mathrm{H}^{+}\right]_{\mathrm{SWS}}=\left[\mathrm{H}^{+}\right]_{\mathrm{SWS} \text { (Hansson) }}$ a priori (which would allow us to replace the sum $\left[\mathrm{H}^{+}\right]_{\mathrm{f}}+\left[\mathrm{HSO}_{4}^{-}\right]+[\mathrm{HF}]$ in Eq. (1) by $\left[\mathrm{H}^{+}\right]$), since our aim here is to set up a generally valid algorithm. Instead, we consider for the time being that the effects of $\mathrm{HSO}_{4}^{-}$and of
HF on total alkalinity are taken into account together with the components of all the other acid systems in the sample, with $K_{\mathrm{HSO}_{4}}$ and $K_{\mathrm{HF}}$ being expressed on the same $\mathrm{pH}$ scale as the constants for those components.

\section{Development of a universal and robust algorithm}

Our ultimate goal here is to develop a universal algorithm to solve the equation

$R_{\mathrm{T}}\left(\left[\mathrm{H}^{+}\right]\right) \equiv \operatorname{Alk}_{\mathrm{nW}}\left(\left[\mathrm{H}^{+}\right]\right)+\frac{K_{\mathrm{W}}}{\left[\mathrm{H}^{+}\right]}-\frac{\left[\mathrm{H}^{+}\right]}{s}-\mathrm{Alk}_{\mathrm{T}}=0$,

where

$\operatorname{Alk}_{\mathrm{nW}}\left(\left[\mathrm{H}^{+}\right]\right)=\sum_{i} \operatorname{Alk}_{\mathrm{A}_{[i]}}\left(\left[\mathrm{H}^{+}\right]\right)$

collects the contributions from all the acid systems to total alkalinity, system by system, proton donors and acceptors combined for each one - except for the contribution that results from the self-ionization of water which we keep explicit in Eq. (21) - and where $\mathrm{Alk}_{\mathrm{T}}$ and all the total concentrations $\left[\Sigma \mathrm{A}_{[i]}\right]$ are given.

We will use a hybrid method that combines the speed of convergence of super-linear and higher-order methods (such as the secant or the Newton-Raphson methods) with the global convergence security of the bisection or the regula falsi method. A similar method is used by the OCMIP carbonate speciation routine. Such methods are standard in root finding for non-linear equations (e.g. Dowell and Jarrett, 1971; Anderson and Björk, 1973; Bus and Dekker, 1975). They are particularly suitable for our problem with its advantageous mathematical characteristics, the more so since that problem also has intrinsic a priori root bracketing, as we will show in the next section. Because of the strict monotonicity of the rational function it is sufficient to make sure that iterates remain within bounds. As long as iterates remain within bounds, they will unconditionally improve either one of the two bounds, thus allowing us to tighten the bracketing interval at each step. We can therefore use a high-order numerical root-finding method, such as Newton-Raphson or the secant method as the main iterative scheme. In case the main scheme yields an out-of-bounds iterate at some step, that iterate is rejected and a bisection iterate is used instead. Similarly, if an iteration with the main scheme does not make the absolute value of the equation decrease faster than expected for a bisection step (i.e. by a factor of two) it is replaced by a bisection step. This helps to prevent cyclic iterations.

A bisection step may temporarily slow down the rate of convergence, but it will secure convergence and again unconditionally improve the bracketing. A regula falsi step could be used instead of bisection; bisection has proven to be more economic though. 


\subsection{Intrinsic bracketing bounds for the root}

Our first aim is now to determine $H_{\mathrm{inf}}>0$ such that $R_{\mathrm{T}}\left(H_{\text {inf }}\right)>0$ and $H_{\text {sup }}>0$ such that $R_{\mathrm{T}}\left(H_{\text {sup }}\right)<0$. We have previously established that $\mathrm{Alk}_{\mathrm{nW}}\left(\left[\mathrm{H}^{+}\right]\right)$is a strictly decreasing rational function for $\left[\mathrm{H}^{+}\right]>0$ and that it has the infimum $\mathrm{Alk}_{\mathrm{nWinf}}=-\sum_{i} m_{i}\left[\Sigma \mathrm{A}_{[i]}\right]$. It is therefore sufficient to have $H_{\text {inf }}$ such that

$\frac{K_{\mathrm{W}}}{H_{\mathrm{inf}}}-\frac{H_{\mathrm{inf}}}{s}=\mathrm{Alk}_{\mathrm{T}}-\mathrm{Alk}_{\mathrm{nWinf}}$,

as in this case $R_{\mathrm{T}}\left(H_{\mathrm{inf}}\right)=\mathrm{Alk}_{\mathrm{nW}}\left(H_{\mathrm{inf}}\right)-\operatorname{Alk}_{\mathrm{nWinf}}>0$. Equivalently, we require that $H_{\mathrm{inf}}^{2}+s\left(\mathrm{Alk}_{\mathrm{T}}-\mathrm{Alk}_{\mathrm{nWinf}}\right) H_{\mathrm{inf}}-$ $s K_{\mathrm{W}}=0$, and $H_{\text {inf }}>0$. This problem has the unique solution

$H_{\mathrm{inf}}=\frac{-s\left(\mathrm{Alk}_{\mathrm{T}}-\mathrm{Alk}_{\mathrm{nWinf}}\right)+\sqrt{\Delta_{\mathrm{inf}}}}{2}$,

where $\Delta_{\mathrm{inf}}=s^{2}\left(\mathrm{Alk}_{\mathrm{T}}-\mathrm{Alk} \mathrm{nWinf}^{2}\right)^{2}+4 s K_{\mathrm{W}}>0$ is the discriminant of the quadratic.

Similarly, because $\mathrm{Alk}_{\mathrm{nW}}\left(\left[\mathrm{H}^{+}\right]\right)$has the supremum $\mathrm{Alk}_{\mathrm{nWsup}}=\sum_{i}\left(n_{i}-m_{i}\right)\left[\Sigma \mathrm{A}_{[i]}\right]$, it is sufficient to chose $H_{\text {sup }}$ such that

$\frac{K_{\mathrm{W}}}{H_{\text {sup }}}-\frac{H_{\text {sup }}}{s}=\mathrm{Alk}_{\mathrm{T}}-\mathrm{Alk}_{\mathrm{nWsup}}$,

which would lead to $R_{\mathrm{T}}\left(H_{\text {sup }}\right)=\operatorname{Alk}_{\mathrm{nW}}\left(H_{\text {sup }}\right)-\mathrm{Alk}_{\mathrm{nWsup}}<$ 0 as requested. Equivalently, we require that $H_{\text {sup }}^{2}+s\left(\mathrm{Alk}_{\mathrm{T}}-\right.$ Alk $\left.\mathrm{n}_{\text {nsup }}\right) H_{\text {sup }}-s K_{\mathrm{W}}=0$ and $H_{\text {sup }}>0$. We finally obtain

$H_{\text {sup }}=\frac{-s\left(\mathrm{Alk}_{\mathrm{T}}-\mathrm{Alk} \mathrm{nW}_{\text {sup }}\right)+\sqrt{\Delta_{\text {sup }}}}{2}$,

where $\Delta_{\text {sup }}=s^{2}\left(\mathrm{Alk}_{\mathrm{T}}-\mathrm{Alk}_{\mathrm{nW} \text { sup }}\right)^{2}+4 s K_{\mathrm{W}}>0$.

$H_{\text {inf }}$ and $H_{\text {sup }}$ define a universal bracketing interval for the root of Eq. (21). They only require information that can be directly derived from the nature of the acid systems considered for $\mathrm{Alk}_{\mathrm{T}}$, and they can theoretically be used with any numerical scheme to keep iterations bracketed right from the start of the scheme, without any need for manually prescribing them.

\subsection{Outline of the algorithm}

The proposed algorithm is formally set up in the $\mathrm{pH}-\mathrm{Alk}_{\mathrm{T}}$ space. There are several advantages for rooting the algorithm in the $\mathrm{pH}-\mathrm{Alk}_{\mathrm{T}}$ space: (1) the equation's overall appearance is closer to linear in the $\mathrm{pH}-\mathrm{Alk}_{\mathrm{T}}$ space than in the more commonly used $\left[\mathrm{H}^{+}\right]-\mathrm{Alk}_{\mathrm{T}}$ space; (2) physically meaningless negative $\left[\mathrm{H}^{+}\right]$values cannot be produced by the iterative scheme; this is not warranted with methods that are rooted in the $\left[\mathrm{H}^{+}\right]-\mathrm{Alk}_{\mathrm{T}}$ space. There is nevertheless also a potential disadvantage: passing between the two spaces a priori requires costly power and logarithm evaluations at each step. As shown below, these operations can, however, be avoided to a large extent by transposing the actual calculations into the $\left[\mathrm{H}^{+}\right]-\mathrm{Alk}_{\mathrm{T}}$ space and carrying them out there.

The algorithm comes in two variants: one based upon the Newton-Raphson and bisection methods, and one that is based upon the secant and bisection methods. We will first describe the Newton-Raphson/bisection variant.

Let $R=R(H)$ denote the rational function chosen to approximate $\mathrm{Alk}_{\mathrm{T}}$. Before starting we determine the intrinsic lower and upper bounds $H_{\text {inf }}$ and $H_{\text {sup }}$, and constrain the initial value $H_{0}$ to be within bounds.

Then, at each step $k+1, k=0, \ldots$ :

1. prepare to carry out a Newton-Raphson step where $\mathrm{pH}_{k+1}=\mathrm{pH}_{k}+\Delta \mathrm{pH}$, with $\Delta \mathrm{pH}=-\left.R\right|_{\mathrm{pH}_{k}} /\left.(\mathrm{d} R / \mathrm{dpH})\right|_{\mathrm{pH}_{k}}:\left.\quad(\mathrm{d} R / \mathrm{dpH})\right|_{\mathrm{pH}_{k}} \quad$ can be calculated from $R\left(H_{k}\right)$ and $\mathrm{d} R /\left.\mathrm{d} H\right|_{H_{k}}$, noticing that $\left.(\mathrm{d} R / \mathrm{dpH})\right|_{\mathrm{pH}_{k}}=-\left.(\mathrm{d} R / \mathrm{d} H)\right|_{H_{k}} \times H_{k} \times \ln (10) ;$

2. adapt the bracketing interval: if $\left.R\right|_{\mathrm{pH}_{k}}>0$ then adjust $H_{\text {inf }}:=H_{k}$, if $\left.R\right|_{\mathrm{pH}_{k}}<0$ then adjust $H_{\text {sup }}:=H_{k}$;

3. require $\left|R\left(H_{k}\right)\right|$ to decrease faster than one would typically expect from bisection under the same conditions: compare it with $\min \left(\left|R\left(H_{j}\right)\right|, \forall j<k\right)$ and if greater than half that value (bisection halves the bracketing interval at each step and is linearly convergent), do not complete the Newton-Raphson step, but adopt a bisection iterate between the current $\mathrm{pH}_{\text {inf }}$ and $\mathrm{pH}_{\text {sup }}$ (updated just before) and return to stage 1 for the next step;

4. provisionally set $H_{k+1}=10^{-\mathrm{pH}_{k+1}}=H_{k} \times$ $\exp \left(-R\left(H_{k}\right) /\left(H_{k} \mathrm{~d} R /\left.\mathrm{d} H\right|_{H_{k}}\right)\right)$ to complete the Newton-Raphson step;

5. constrain $H_{k+1}$ to remain within the current bracketing interval: if $H_{k+1}>H_{\text {sup }}$ or $H_{k+1}<H_{\text {inf }}$, reject the Newton-Raphson iterate, replace it by the bisection iterate as in stage 4 and return to stage 1 for the next step;

6. stop the iterations if either the maximum permissible number of iterations is exceeded or if $\mid\left(H_{k+1}-\right.$ $\left.H_{k}\right) / H_{k} \mid<\epsilon(\epsilon$ being a pre-set tolerance $)$, else return to stage 1 for another step.

At most, one exponential has to be evaluated per step (at stage 4). This is, computationally speaking, the most expensive operation in each step. It can, however, often be avoided: when $\left|R_{\mathrm{T}}\left(H_{k}\right) /\left(H_{k} \mathrm{~d} R /\left.\mathrm{d} H\right|_{H_{k}}\right)\right| \ll$, then $\left.\quad H_{k} \times \exp \left(-R_{\mathrm{T}}\left(H_{k}\right) /\left.\left(H_{k} \quad \mathrm{~d} R / \mathrm{d} H\right)\right|_{H_{k}}\right)\right) \simeq$ $H_{k}-R_{\mathrm{T}}\left(H_{k}\right) /\left(\mathrm{d} R /\left.\mathrm{d} H\right|_{H_{k}}\right)$ and the iterate can be assimilated to a plain $\left[\mathrm{H}^{+}\right]-\mathrm{Alk}_{\mathrm{T}}$ space Newton-Raphson iterate. Once the argument of the exponential becomes sufficiently small (a threshold value of 1 in absolute value has proven efficient) we may switch to the linear approximation, thereby saving the exponential operation. The relative error $\left|\left(H_{k+1}-H_{k}\right) / H_{k}\right|$ from the stopping criterion can be approximated by $\left|R\left(H_{k}\right) /\left(H_{k} \mathrm{~d} R /\left.\mathrm{d} H\right|_{H_{k}}\right)\right|$, i.e. we 
can reuse the argument of the exponential above (no extra operations required). At any stage, bisection between $\mathrm{pH}_{\mathrm{inf}}$ and $\mathrm{pH}_{\text {sup }}$ translates to calculating $H_{k+1}$ as the geometric mean of $H_{\text {inf }}$ and $H_{\text {sup }}: H_{k+1}=\sqrt{H_{\text {inf }} H_{\text {sup }}}$. By construction, any accepted iterate will thus be strictly between the current $H_{\text {inf }}$ and $H_{\text {sup }}$, and, because of the strictly decreasing nature of $R(H)$, will always lead to contribute to improve either the lower or the upper bound.

In a variant of the above we replace the Newton-Raphson scheme by a secant scheme. However, rooting a secant scheme in the $\mathrm{pH}-\mathrm{Alk}_{\mathrm{T}}$ space while carrying out operations in the $\left[\mathrm{H}^{+}\right]-\mathrm{Alk}_{\mathrm{T}}$ space will require non-integer power operations at each step which are even more costly than exponentials. It is therefore preferable to completely root the calculations in the $\left[\mathrm{H}^{+}\right]-\mathrm{Alk}_{\mathrm{T}}$ space with the secant method, despite the potential trade-offs for the convergence efficiency. Secant iterations have the advantage of requiring only one evaluation of the equation at each iteration; in addition to the equation evaluation, Newton-Raphson iterations also require the evaluation of the derivative of the equation. The cheaper iterations of the secant method possibly outweigh its lower order of convergence, which is $\simeq 1.62$, compared to 2 for the Newton-Raphson method.

\subsection{Discussion: comparison with the OCMIP solver}

A similar technique was also used in the drtsafe routine in the OCMIP suite (Orr et al., 2000), which is fundamentally the rtsafe routine of Press et al. (1989) with some essential error trapping removed. That routine also combines the global convergence properties of the bisection with the speed of convergence of the Newton-Raphson method.

The algorithm presented here differs from that used in drtsafe in several significant ways. (1) drtsafe iterations are rooted in the $\left[\mathrm{H}^{+}\right]-\mathrm{Alk}_{\mathrm{T}}$ space. (2) drtsafe requires brackets to be explicitly provided at the subroutine call. In case these are inappropriate (e.g. no sign change of the equation function over the defined bracketing interval), it would simply iterate to the maximum number of iterations allowed because of the absence of validity checks and return some meaningless result (in general one of the two bounds provided). (3) drtsafe always starts its iterations from the midpoint of the provided bracketing interval. It is thus critically dependent on a valid interval (no validity checks performed though) and, because of the rooting in the $\left[\mathrm{H}^{+}\right]-\mathrm{Alk}_{\mathrm{T}}$ space, on a tight bracketing interval for efficiency. The algorithms proposed here only use the bracketing values to secure convergence in case Newton-Raphson iterates are not decreasing fast enough or would go out of bounds, and they use an independent initial value. Because we root our iterations in the $\mathrm{pH}-\mathrm{Alk}_{\mathrm{T}}$ space, even bisection steps may accommodate $\left[\mathrm{H}^{+}\right]$changes over several orders of magnitude during the initial steps in case a far off starting value is used.

\section{Sample implementation of the new algorithms in Fortran 90}

A sample implementation of the algorithms realized in standard Fortran 90 is provided in the Supplement to this paper. Together with the drivers that were used to carry out the experiments described below they make up the Solver Suite for Alkalinity-PH Equations (SolveSAPHE). Parts of the code contain C-preprocessor directives for enabling or disabling specific parts (debugging messages, optional code parts, etc.), and to select among the cases treated below. After pre-processing, the source files are strictly standard conforming Fortran 90. The codes are made available under the GNU Lesser Public Licence, version 3.

A complete user manual that covers the technical details of SolveSAPHE is included in the archive provided in the Supplement. Here we only give a short overview of the two central modules.

\subsection{Summary description}

The module mod_chemconst provides parametric expressions for the stoichiometric constants of the acid systems taken into account (carbonates, borates, hydrogen sulphate, sulphides, phosphates, etc.). The module also hosts the $\Pi_{j}$ values (Eq. 5) for the various acid systems.

The module mod_phsolvers provides six different solvers:

1. the function solve_at_general: the new algorithm described above;

2. the function solve_at_icacfp: a fixed-point only ICAC method;

3. the function solve_at_bacastow: Bacastow's method, an ICAC method with secant iterations (with secant iterations either on $\left[\mathrm{H}^{+}\right]$or on its scaled inverse);

4. the function solve_at_general_sec: the variant of solve_at_general that uses secant instead of Newton-Raphson iterations;

5. the function solve_at_ocmip: a re-implementation of the OCMIP solver with Newton-Raphson/bisection iterations, completed with a bare minimum of error trapping and fitted with the optional initialization scheme common to all of the solvers (the latter was only adapted to use an interval of $\pm 0.5 \mathrm{pH}$ unit interval around an optional initial value to emulate the recommended OCMIP set-up after start-up);

6. the function solve_at_fast: a simplified version of solve_at_general without the bracketing control (may not always converge).

Each one of the six solvers takes into account all of the constituents that explicitly appear in Eq. (1), except 
for $\mathrm{S}^{2-}$ whose concentration is negligible even at high $\mathrm{pH}$ values. mod_phsolvers_logging.F90 is a special version of mod_phsolvers.F90 that includes extra bookkeeping regarding the number of iterations required for convergence, the numbers of bisection iterations due to limiting, the initial values adopted, the initial bracketing values (if relevant), the intermediate iterates, etc. mod_phsolvers_logging.F90 does not include solve_at_fast though. For more technical details, please refer to the manual that goes with the source codes.

The modules mod_acb_solvers and mod_acbw_solvers provide simpler and more streamlined solvers, based upon the $\mathrm{Alk}_{\mathrm{CB}}$ and $\mathrm{Alk}_{\mathrm{CBW}}$ approximations, respectively. In these, we assume, e.g. that $\left[\mathrm{H}^{+}\right]_{\mathrm{f}}+\left[\mathrm{HSO}_{4}^{-}\right]+[\mathrm{HF}]=\left[\mathrm{H}^{+}\right]_{\mathrm{SwS}}$.

\subsection{Test case definitions}

The list of species considered in the approximation of $\mathrm{Alk}_{\mathrm{T}}$ adopted in the six solvers presented here are much more complete than absolutely necessary in global biogeochemical cycle models. Most of these call upon the $\mathrm{Alk}_{\mathrm{CBW}}$ approximation for $\mathrm{Alk}_{\mathrm{T}}$, which requires only $\mathrm{Alk}_{\mathrm{CBW}}, C_{\mathrm{T}}$ and $B_{\mathrm{T}}$ to be known, the two former being generally controlled by conservation equations, the latter taken proportional to salinity. A few models, essentially those using the complete OCMIP solver, also take into account the small contributions of phosphate alkalinity $\left(\mathrm{Alk}_{\mathrm{P}}=\left[\mathrm{HPO}_{4}^{2-}\right]+2 \times\left[\mathrm{PO}_{4}^{3-}\right]-\left[\mathrm{H}_{3} \mathrm{PO}_{4}\right]\right)$ and silicate alkalinity $\left(\mathrm{Alk}_{\mathrm{Si}}=\left[\mathrm{H}_{3} \mathrm{SiO}_{4}^{-}\right]\right)$. They therefore either include conservation equations or prescribed distributions for total dissolved phosphate and total dissolved silicate.

For our test cases, we focus on the influence of various combinations of $C_{\mathrm{T}}$ and $\mathrm{Alk}_{\mathrm{T}}$ on the convergence properties of the six solvers. For all the other acid dissociation systems that are taken into account in the solver routines, we adopt constant total concentrations (see below).

The $\mathrm{pH}_{\mathrm{SWS}}$ scale was adopted for all of the calculations. With each method, iterations were stopped once the relative change of an iterate compared to its predecessor fell below $10^{-8}$; the maximum number of iterations was set to 50 . For all of the three cases, we adopt a temperature of $275.15 \mathrm{~K}$, a salinity of 35 and an applied pressure of 0 bar. Additional results for a temperature of $298.15 \mathrm{~K}$ or a pressure of $300 \mathrm{bar}$ can be found in the Supplement.

The convergence properties for each one of the $\mathrm{pH}$ solvers are explored for three different (nested) subsets of the $C_{\mathrm{T}}-\mathrm{Alk}_{\mathrm{T}}$ space:

SW1 - for $C_{\mathrm{T}}$ ranging between $1.85 \mathrm{mmolkg}^{-1}$ and $2.45 \mathrm{mmol} \mathrm{kg}^{-1}$, and $\mathrm{Alk}_{\mathrm{T}}$ between $2.20 \mathrm{meq} \mathrm{kg}^{-1}$ and $2.50 \mathrm{meq} \mathrm{kg}^{-1}$, on a regular $600 \times 300$ cell centred grid;
$\mathrm{SW} 2$ - for $C_{\mathrm{T}}$ ranging between $1.85 \mathrm{mmolkg}^{-1}$ and $3.35 \mathrm{mmolkg}^{-1}$, and $\mathrm{Alk}_{\mathrm{T}}$ between $2.20 \mathrm{meq} \mathrm{kg}^{-1}$ and $3.50 \mathrm{meq} \mathrm{kg}^{-1}$, on a regular $1500 \times 1300$ cell centred grid ${ }^{3}$

SW3 - for $C_{\mathrm{T}}$ ranging between $0 \mathrm{mmolkg}^{-1}$ and $6 \mathrm{mmolkg}^{-1}$, and Alk $\mathrm{T}$ between $-1 \mathrm{meq} \mathrm{kg}^{-1}$ and $5 \mathrm{meq} \mathrm{kg}^{-1}$, on a regular $600 \times 600$ cell centred grid.

The other concentrations are set as follows: $P_{\mathrm{T}}=$ $0.5 \mu \mathrm{mol} \mathrm{kg}{ }^{-1}, \quad \mathrm{Si}_{\mathrm{T}}=5 \mu \mathrm{mol} \mathrm{kg} \mathrm{kg}^{-1}, \quad\left[\mathrm{NH}_{4}\right]_{\mathrm{T}}=0 \mu \mathrm{molkg}-1$ and $\left[\mathrm{H}_{2} \mathrm{~S}\right]_{\mathrm{T}}=0 \mu \mathrm{mol} \mathrm{kg}{ }^{-1}$. With each test case, three different schemes are considered to start the iterations: (cub) starting values are derived from the scheme designed for the cubic polynomial in Sect. 3.2.2; (pH8) a constant starting value $\left[\mathrm{H}^{+}\right]=10^{-8} \mathrm{~mol} \mathrm{~kg}^{-1}$ is used, except for solve_at_ocmip, for which the recommended "cold-start" brackets corresponding to $\mathrm{pH}=6$ and $\mathrm{pH}=9$ are used; (safe) the midpoint of the $\mathrm{pH}$ interval defined by the intrinsic brackets $H_{\text {inf }}$ and $H_{\text {sup }}$ (from Sect. 5.1) is used as a starting value, except for solve_at_ocmip, for which $H_{\text {inf }}$ and $H_{\text {sup }}$ are used as initial brackets. Timing information is based upon driver_at_general.F90, all other information (numbers of iterations, of divergences, errors, etc.) upon driver_at_logging.F 90.

SW1 covers the typical range of present-day seawater samples. Every solver should be able to determine the root of the equation without a single failure. SW2 covers the expected range of sea-water samples under the S750 stabilization scenario over the next $50000 \mathrm{yr}$ (derived from simulation experiments with the coupled carbon cycle-sediment model MBM-MEDUSA, Munhoven, 2007, 2009). SW3 is of more theoretical nature and is meant to analyse the performance of the solvers with extremely low alkalinity or $C_{\mathrm{T}}$ values. It will nevertheless also provide important information about the convergence domains of solve_at_icacfp and solve_at_bacastow, as we will see below.

\subsection{Results}

We here only present results obtained with the solvers from mod_phsolvers (for the timings) and mod_phsolvers_logging. To simplify the presentation, we leave out the prefix "solve_at_" when referring to the different solver functions below. The testing platform had a Debian 6.0.6 operating system (32 bit kernel 2.6.32-5-686bigmem) running on a $2.53 \mathrm{GHz}$ Intel Core2Duo T9400 $\mathrm{CPU}$; all of the source codes were compiled with gfortran 4.4.5, without any optimization flags set.

\footnotetext{
${ }^{3}$ For the graphs shown below, a $150 \times 130$ cell centred grid was used.
} 
Table 1. Execution times for the SW1, SW2 and SW3 tests, each one with the three initialization types (see text). Crosses ( $\times$ ) indicate test series that were affected by divergences and could not be considered for time measurements (notice one exception); dashes (-) indicate that the experiment was not carried out. Within each one of the groups SW1, SW2 and SW3, figures were normalized to the execution time of the respective "cub" run with general_sec and rounded to the nearest multiple of 0.05 (i.e. the order of the the largest standard deviation). "cub" results for general_sec are reported in italics as they have been implicitly set to exactly 1 by the normalization procedure and are not affected by the rounding procedure.

\begin{tabular}{|c|c|c|c|c|c|c|c|c|c|}
\hline \multirow[t]{2}{*}{ Routine } & \multicolumn{3}{|c|}{ SW1 } & \multicolumn{3}{|c|}{ SW2 } & \multicolumn{3}{|c|}{ SW3 } \\
\hline & cub & pH8 & safe & cub & $\mathrm{pH} 8$ & safe & $\mathrm{cub}$ & $\mathrm{pH} 8$ & safe \\
\hline general & 1.05 & 1.55 & 1.65 & 1.05 & 1.60 & 1.65 & 1.10 & 1.65 & 1.75 \\
\hline general_sec & 1.00 & 1.45 & 1.60 & 1.00 & 1.60 & 1.55 & 1.00 & 1.55 & 1.55 \\
\hline fast & 0.95 & 1.50 & 1.70 & 1.00 & 1.65 & $1.90^{*}$ & $x$ & $\times$ & $x$ \\
\hline icacfp & 2.35 & 2.90 & - & 1.75 & 2.10 & - & $x$ & $x$ & - \\
\hline bacastow & 0.90 & 1.15 & - & 0.85 & 1.10 & - & $x$ & $x$ & - \\
\hline ocmip & 1.85 & 3.15 & 5.70 & 1.75 & $\times$ & 5.60 & $\times$ & $x$ & 3.70 \\
\hline
\end{tabular}

* Note: includes one divergent case on 1950000 calls.

\subsubsection{Comparison of the six solvers}

Figure 1 shows the distributions of $\mathrm{pH}$ for test cases SW1, SW2 and SW3, as calculated by the new algorithm with Newton-Raphson iterations. Also shown is the equation residual for SW3 (which encompasses the two others). Residual values smaller than $10^{-21} \mathrm{~mol} \mathrm{~kg}^{-1}$ in absolute value are shown as $10^{-21} \mathrm{~mol} \mathrm{~kg}^{-1}$. The residual is at least five orders of magnitude smaller than the actual $\mathrm{H}^{+}$concentrations, emphasizing that convergence was significantly reached.

Execution times for the SW1, SW2 and SW3 test series are reported in Table 1 . The times for each of the three test series have been normalized to the execution time of the general_sec routine with cubic initialization (shown in italics). general_sec was the fastest of the routines that successfully passed the complete test series.

For test cases SW1 and SW2, Bacastow's method is clearly the fastest. It is about $20 \%$ faster than the general and general_sec routines developed here, and twice or two and a half times as fast as its closest relative icacfp. general_sec is generally about $5-10 \%$ faster than general. The results obtained with fast indicate that the overhead required by the safeguard bracketing requires about 5-10\% extra computing time, if everything works fine. However, the comparison of the SW2-pH8 results for general and fast shows that replacing unacceptable Newton-Raphson steps by safe but inherently slower bisection steps may overall even lead to a gain of time in more critical situations. Neither fast, nor bacastow, nor i cacfp were able to complete test case SW3; ocmip was furthermore not able to complete the SW2-pH8 test, because of invalid initial bracketing over parts of the domain. Convergence failures with ocmip can be avoided if we use the intrinsic bracketing bounds obtained in Sect. 5.1, as can be seen from the "safe" initialization procedure. However, with this safe initialization procedure, the execution for ocmip exceed those of general_sec with the cubic initialization by a factor of 5.6-5.7 in test case SW1 and SW2, and by a factor of 3.7 for case SW3. As can be seen in Fig. 1, SW3 includes a large number of $C_{\mathrm{T}}-\mathrm{Alk}_{\mathrm{T}}$ combinations that lead to extreme $\mathrm{pH}$ values (either lower than 4 or higher than 10), where the intrinsic bounds are comparatively restrictive.

In each test, and with every method used, the initialization procedure developed above for the cubic polynomial leads to $30-60 \%$ shorter execution times than the constant initialization ("pH8") which may even lead to divergence (e.g. ocmip).

The reasons for the strong performance loss of icacfp in SW1 become obvious in Fig. 2. The figure shows the number of iterations required to trigger the stopping criterion for the SW2 test. The SW1 domain is included at the lower left of the SW2 domain: it ends at $C_{\mathrm{T}}=2.45 \mathrm{mmol} \mathrm{kg}^{-1}$ and $\mathrm{Alk}_{\mathrm{T}}=$ $2.50 \mathrm{meq} \mathrm{kg}^{-1}$. In that area, general and bacastow require at most four iterations, $\mathrm{ocmip}$ generally six or seven, but icacfp often fifteen and more.

\subsubsection{Shortcomings of ICAC methods}

As we have seen, ICAC methods have divergence problems on the SW3 grid. These problems are inherent to the method and can only be alleviated to a limited extent. It should be noticed that the fixed-point equation $H=Q(H)$ (see Eq. 11) has a solution, i.e. that $Q(H)$ has a fixed-point, for any $C_{\mathrm{T}}-\mathrm{Alk}_{\mathrm{T}}$ pair, since the total alkalinity-pH equation has a solution.

The divergence pattern of the ICAC methods can easily be explained from the derivative of the underlying function $Q$ with respect to $H$, shown for SW3 in Fig. 3. The values were calculated from the $\mathrm{H}^{+}$concentrations shown in Fig. 1. The derivative values are negative over the whole domain and fixed-point iterations thus oscillate around the solution (i.e. the fixed point of $Q$ ). Fixed-point iterations can only converge to the fixed point of $Q$ where the derivative is strictly 

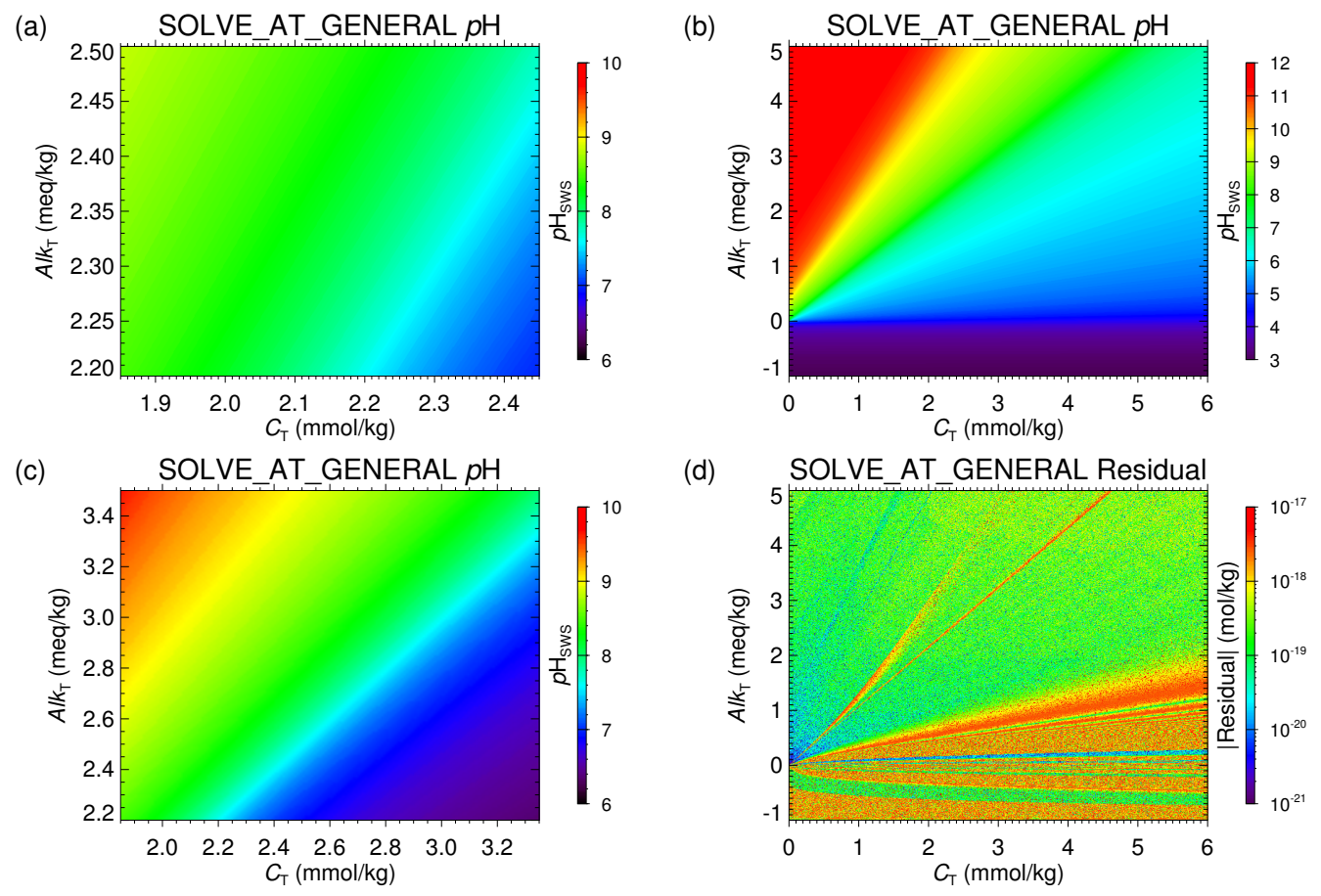

Fig. 1. $\mathrm{pH}_{\text {SWS }}$ values obtained with the new universal algorithm (general) for test cases (a) SW1, (c) SW2 and (b) SW3 - please notice the extended colour scale. (d) Absolute value of the equation residual at the adopted root value, derived with that same algorithm started with the cubic-based initialization to solve test case SW3. Applied convergence criterion: $\left|H_{n+1}-H_{n}\right| / H_{n}<10^{-8}$.

(a)

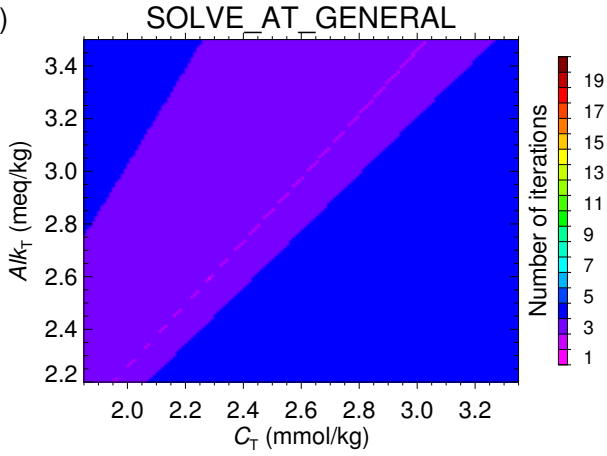

(c)

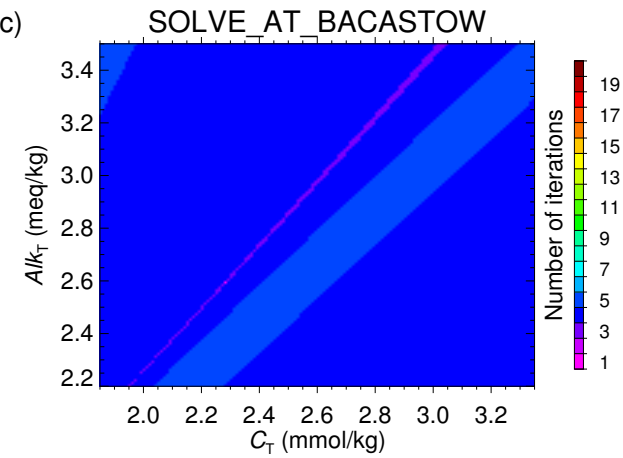

(b)

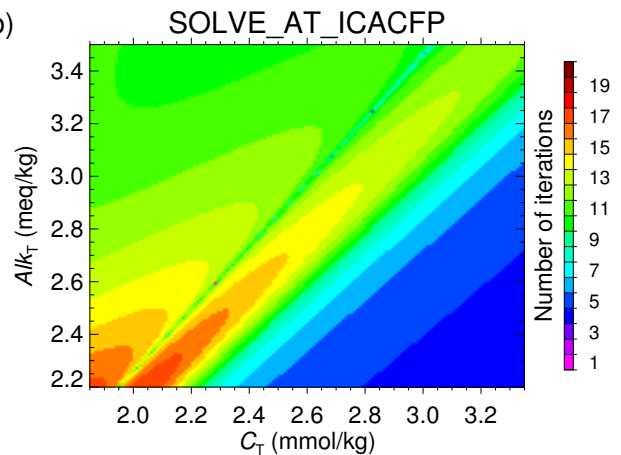

(d)

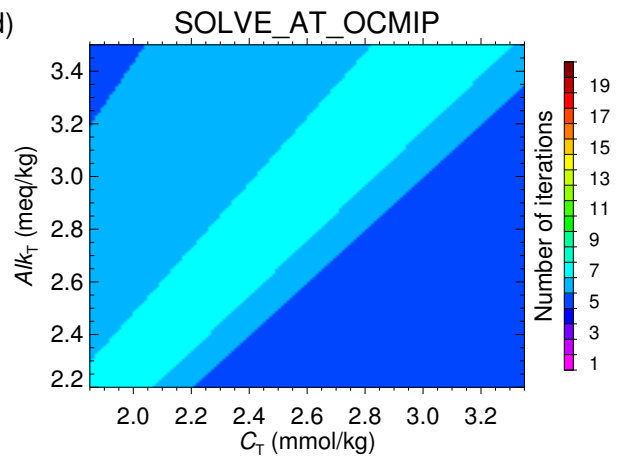

Fig. 2. Number of iterations required by (a) general, (b) icacfp, (c) bacastow with secant iterations on $\left[\mathrm{H}^{+}\right]$and $(\mathbf{d}) \circ \mathrm{cmip}$, each one using the cubic-based initialization procedure to solve test case SW2. Applied convergence criterion: $\left|H_{n+1}-H_{n}\right| / H_{n}<10^{-8}$. 
(a)

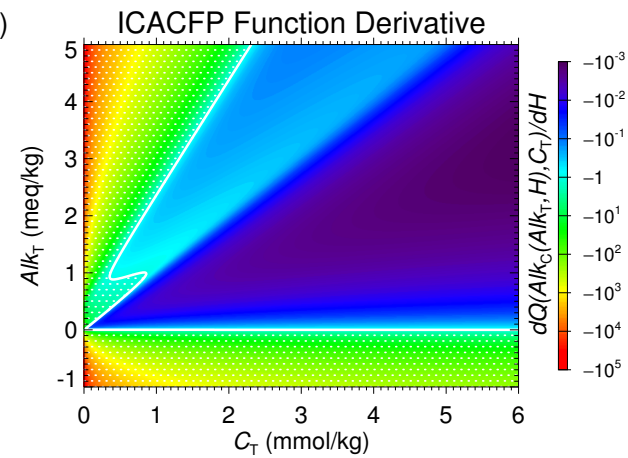

(c)

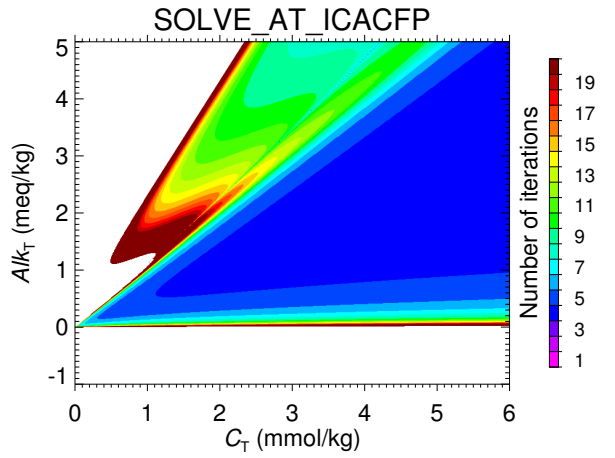

(b)

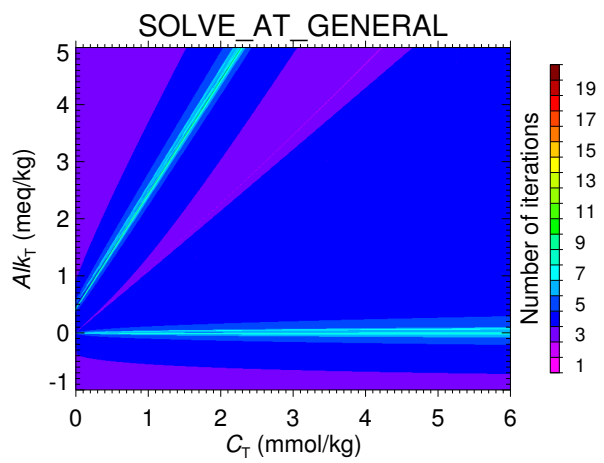

(d)

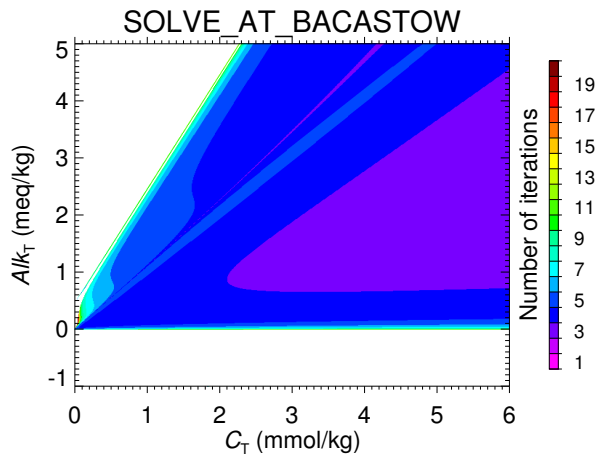

Fig. 3. (a) Derivative with respect to $H$ of the function underlying the ICAC methods, i.e. of the function $Q$ given by Eqs. (9) and (10) that defines the recurrence $H_{n+1}=Q\left(\operatorname{Alk}_{\mathrm{C}}\left(\mathrm{Alk}_{\mathrm{T}}, H_{n}\right), C_{\mathrm{T}}\right)$. The white line indicates where the derivative is equal to -1 ; in the stippled area, the derivative is strictly lower than -1 . Also shown are the numbers of iterations required to meet the convergence criterion for (b) general, (c) icacfp and (d) bacastow with secant iterations on $\left[\mathrm{H}^{+}\right]$. White areas indicate no convergence or an excessive number of iterations $(n>50)$.

smaller than 1 in absolute value, i.e. is strictly greater than -1 here. The thick white line indicates where the derivative of $Q$ is equal to -1 . The white areas on the other graphs indicate where the methods did not converge. The white areas for icacfp clearly match the areas where the derivative of $Q$ is lower than -1 , and they are even somewhat larger.

When the derivative of $Q$ is just slightly greater than -1 , iterations may become "operationally divergent": the pre-set maximum number of iterations is insufficient to meet the stopping criterion as the generated suite converges too slowly there. Bacastow's method, on the other hand, has a slightly larger convergence domain than delimited by the thick white line in the graph of the derivative. The fixed-point equation can indeed be solved by the secant method in some instances where straight fixed-point iterations would produce slowly divergent iteration suites. As the derivative of $Q$ is negative, fixed-point iterations oscillate around the root as long as they can be evaluated, i.e. as long as the $\mathrm{Alk}_{\mathrm{C}}$ estimates obtained from $\mathrm{Alk}_{\mathrm{T}}$ with the $H$ iterates range between 0 and $2 C_{\mathrm{T}}$. If they can be successfully calculated, the two first iterates used to initialize the secant iterations in Bacastow's method thus bracket the root and we may expect that the first application of the secant method provides an excellent estimate for the root, even if the two first iterates would generate a fixed-point suite that slowly diverges. This is especially obvious inside the white bulge in Fig. $3 \mathrm{c}$ at low $C_{\mathrm{T}}$ values and $\mathrm{Alk}_{\mathrm{T}}$ values greater than $C_{\mathrm{T}}$.

\subsubsection{Quality of the cubic equation based initialization}

As shown above, the initialization scheme especially designed for the iterative solution of the cubic Eq. (13) by the Newton-Raphson method is highly attractive even for more complex approximations to total alkalinity than $\mathrm{Alk}_{\mathrm{CB}}$. This is quantified in Fig. 4, exemplified by SW2 results. The relative error of $H_{0}$, determined as outlined in Sect. 3.2.2, on the actual $\mathrm{H}^{+}$concentration (as calculated with general) is less than $7 \%$ over the SW2 domain. In comparison, over that same domain, the approximation $\mathrm{Alk}_{\mathrm{C}} \simeq \mathrm{Alk}_{\mathrm{T}}$ and usage of Eq. (8) gives rise to errors that are about ten times as large.

\section{Conclusions}

We have explored the mathematical properties of the total alkalinity-pH equation, i.e. the equation that relates $\left[\mathrm{H}^{+}\right]$(or equivalently $\mathrm{pH}$ ) to total alkalinity and the total concentrations of all the acid systems contributing to total alkalinity. 
(a)

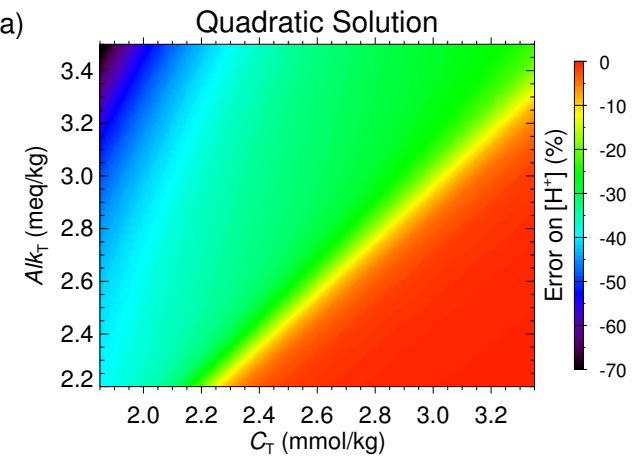

(b)

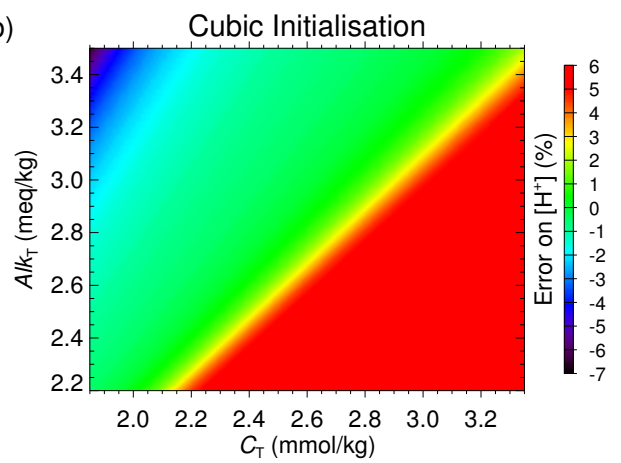

Fig. 4. (a) Relative deviation (in \%) of the solution of the quadratic Eq. (8), calculated by setting $A \mathrm{Al}_{\mathrm{C}}=A \mathrm{Al}_{\mathrm{T}}$, from the actual root of the complete system; (b) idem for the cubic polynomial based initial $\left[\mathrm{H}^{+}\right]$, calculated by setting $\mathrm{Alk}_{\mathrm{CB}}=\mathrm{Alk}_{\mathrm{T}}$. Please notice the strongly different colour scales (underlying data come from test case SW2).

We have demonstrated that the rational function expression of that equation is strictly monotone. If water self-ionization is considered, the total alkalinity-pH equation has one and only one positive root, for any given value of total alkalinity and for any given non-negative values for the total concentrations of the acid system components of total alkalinity. All other roots of the equation are either negative or complex with non-zero imaginary parts. We have shown that there are intrinsic upper and lower bounds for the positive root of the equation that only depend on information from the list of included acid systems. These seemingly straightforward mathematical properties have apparently not been published before and currently available solvers do not take advantage of them. They actually enabled us to design a universal and failsafe algorithm to solve the total alkalinity-pH equation. We propose two variants, one using the Newton-Raphson, the other the secant scheme.

The performances of the two algorithms (plus one simplified version without safe-guarded iterations) were compared with some common existing ones: (1) the fixed-point iterative carbonate alkalinity correction method (ICAC), a classical method recently made popular again by Follows et al. (2006); (2) the method of Bacastow (1981), which is a variant of the previous one using secant instead of fixed-point iterations and (3) the OCMIP-2 standard protocol routines (Orr et al., 2000), re-implemented here. Source code with a reference implementation of the six algorithms discussed in the text is provided in the Solver Suite for Alkalinity-PH Equations (SolveSAPHE) in the Supplement for use under the GNU Lesser General Public Licence version 3 (LGPLv3).

We have defined three test cases for a comparative analysis of the six methods: one for the typical open-ocean concentrations of total dissolved inorganic carbon and total alkalinity of the present-day ocean; another one covering the expected future distributions of these concentrations under progressing ocean acidification and subsequent dissolution of deepsea surface sedimentary carbonates; and a third one covering extremely low concentrations of dissolved inorganic carbon and total alkalinity, and even negative values for total alkalinity. Different approaches for starting iterative root-finding methods have been tested as well for their efficiency.

The two new algorithms are the only ones that successfully complete all of the tests. The same convergence security could be achieved with the OCMIP solver as well after a modification of its initialization scheme, though at the price of much longer execution times (typically by a factor of three to six). Bacastow's method is the fastest of all the tested general methods overall in the common regions of convergence. The two new algorithms are only 10-20\% slower than Bacastow's method and more than $50 \%$ faster than the next best performant ones. The secant variant of our algorithm is about $5-10 \%$ faster than the Newton-Raphson variant. We have developed an original starting scheme for solving the cubic polynomial equation that is to be solved to determine $\mathrm{pH}$ from carbonate and borate alkalinity alone. That starting scheme can easily be completed for usage with general total alkalinity-pH equation solvers and we show here that it typically allows one to save $30-60 \%$ of calculation time compared to the standard $\mathrm{pH}=8$ initialization.

The two proposed algorithms are furthermore extremely robust. As documented in the Supplement, the sample implementation has been successfully used with random values (covering up to six orders of magnitude) for the total concentrations of the acid system components to total alkalinity and of total alkalinity itself, with random $\mathrm{pH}$ starting values between 1 and 14, and still ensured convergence in $100 \%$ of the cases.

The two new algorithms proposed thus practically offer convergence security over an extremely wide range of total concentrations for the contributions of the various acid systems to total alkalinity, while only at a marginal additional computational cost. 


\section{Appendix A}

Alkalinity components are strictly decreasing with $\left[\mathrm{H}^{+}\right]$: demonstration

We are now going to show that

$\frac{\mathrm{dAlk}_{\mathrm{A}}}{\mathrm{d}\left[\mathrm{H}^{+}\right]}<0$

for any given acid system $\mathrm{H}_{n} \mathrm{~A}-\mathrm{H}_{n-1} \mathrm{~A}^{-}-\ldots-\mathrm{A}^{n-}$, i.e. for constant $[\Sigma \mathrm{A}]$, at equilibrium.

For notational convenience, we write

$\mathrm{Alk}_{\mathrm{A}}=[\Sigma \mathrm{A}]\left(\frac{D_{1}}{D}-m\right)$

with

$D=\sum_{j=0}^{n} \Pi_{j}\left[\mathrm{H}^{+}\right]^{n-j} \quad$ and $\quad D_{1}=\sum_{j=0}^{n} j \Pi_{j}\left[\mathrm{H}^{+}\right]^{n-j}$.

Since $\Pi_{j}>0$ for any $j \geq 0$, we know that $D>0$ and $D_{1}>$ 0 . We may then write

$\frac{\mathrm{dAlk}_{\mathrm{A}}}{\mathrm{d}\left[\mathrm{H}^{+}\right]}=[\Sigma \mathrm{A}] \frac{\mathrm{d}}{\mathrm{d}\left[\mathrm{H}^{+}\right]}\left(\frac{D_{1}}{D}\right)=[\Sigma \mathrm{A}] \frac{D \frac{\mathrm{d} D_{1}}{\mathrm{~d}\left[\mathrm{H}^{+}\right]}-D_{1} \frac{\mathrm{d} D}{\mathrm{~d}\left[\mathrm{H}^{+}\right]}}{D^{2}}$.

It is straightforward to show that

$\frac{\mathrm{d} D}{\mathrm{~d}\left[\mathrm{H}^{+}\right]}=\frac{1}{\left[\mathrm{H}^{+}\right]}\left(n D-D_{1}\right)$

and

$\frac{\mathrm{d} D_{1}}{\mathrm{~d}\left[\mathrm{H}^{+}\right]}=\frac{1}{\left[\mathrm{H}^{+}\right]}\left(n D_{1}-D_{2}\right)$,

where we have further defined

$D_{2}=\sum_{j=0}^{n} j^{2} \Pi_{j}\left[\mathrm{H}^{+}\right]^{n-j}$,

which is positive, similarly to $D$ and $D_{1}$. We hence find that

$$
\begin{aligned}
\frac{\mathrm{dAlk}_{\mathrm{A}}}{\mathrm{d}\left[\mathrm{H}^{+}\right]} & =[\Sigma \mathrm{A}] \frac{D\left(n D_{1}-D_{2}\right)-D_{1}\left(n D-D_{1}\right)}{\left[\mathrm{H}^{+}\right] D^{2}} \\
& =-[\Sigma \mathrm{A}] \frac{D D_{2}-D_{1}^{2}}{\left[\mathrm{H}^{+}\right] D^{2}} .
\end{aligned}
$$

The result now follows from Lagrange's identity:

$$
\begin{aligned}
& \left(\sum_{j=0}^{n} x_{j}^{2}\right)\left(\sum_{j=0}^{n} y_{j}^{2}\right)-\left(\sum_{j=0}^{n} x_{j} y_{j}\right)^{2} \\
& =\frac{1}{2} \sum_{j=0}^{n} \sum_{i=0}^{n}\left(x_{i} y_{j}-x_{j} y_{i}\right)^{2} .
\end{aligned}
$$

With

$x_{j}=\sqrt{\Pi_{j}\left[\mathrm{H}^{+}\right]^{n-j}}$,

$y_{j}=j \sqrt{\Pi_{j}\left[\mathrm{H}^{+}\right]^{n-j}}$,

we have

$\sum_{j=0}^{n} x_{j}^{2}=D, \quad \sum_{j=0}^{n} y_{j}^{2}=D_{2} \quad$ and $\quad \sum_{j=0}^{n} x_{j} y_{j}=D_{1}$.

To conclude, it is then sufficient to notice that

$\sum_{j=0}^{n} \sum_{i=0}^{n}\left(x_{i} y_{j}-x_{j} y_{i}\right)^{2}=\sum_{j=0}^{n} \sum_{i=0}^{n} \Pi_{i} \Pi_{j}(i-j)^{2}\left[\mathrm{H}^{+}\right]^{2 n-i-j}$,

which is strictly positive if $n>0$. Alternatively, the result also follows from the Cauchy-Schwarz inequality in $n+1$ dimensions, noticing that the conditions for equality are not met.

Accordingly, $\mathrm{Alk}_{\mathrm{A}}\left(\left[\mathrm{H}^{+}\right]\right)$is strictly decreasing as a function of $\left[\mathrm{H}^{+}\right]$.

\section{Supplementary material related to this article is available online at: http://www.geosci-model-dev.net/6/ 1367/2013/gmd-6-1367-2013-supplement.zip.}

Acknowledgements. I sincerely thank Mick Follows and the anonymous reviewer, the topical editor Andy Ridgwell, as well as Alberto Borges and Anne Mouchet for their comments on the discussion manuscript and for their suggestions on how to improve it. Alberto Borges, Jérôme Harlay, Marc-Vincent Commarieu and Tom Munhoven patiently provided essential explanations on the art of $\mathrm{pH}$ measurement. Financial support for this publication was provided by the Belgian Fund for Scientific Research - FNRS (FRFC grant 2.4571.10). Guy Munhoven is a Research Associate with the Belgian Fund for Scientific Research - FNRS.

Edited by: A. Ridgwell

\section{References}

Anderson, N. and Björk, A.: A new high order method of regula falsi type for computing a root of an equation, BIT, 13, 253-264, 1973.

Antoine, D. and Morel, A.: Modelling the seasonal course of the upper ocean $p \mathrm{CO}_{2}$ (I). Development of a one-dimensional model, Tellus B, 47, 103-121, doi:10.1034/j.1600-0889.47.issue1.11.x, 1995.

Arndt, S., Regnier, P., Goddéris, Y., and Donnadieu, Y.: GEOCLIM reloaded ( $\mathrm{v}$ 1.0): a new coupled earth system model for past climate change, Geosci. Model Dev., 4, 451-481, doi:10.5194/gmd-4-451-2011, 2011.

Aumont, O. and Bopp, L.: Globalizing results from ocean in situ iron fertilization studies, Global Biogeochem. Cy., 20, GB2017, doi:10.1029/2005GB002591, 2006. 
Bacastow, R.: Numerical evaluation of the evasion factor, in: Carbon Cycle Modelling, vol. 16 of SCOPE, chap. 3.4, edited by: Bolin, B., John Wiley \& Sons, Chichester, NY, 95-98, 1981.

Bacastow, R. and Keeling, C. D.: Atmospheric carbon dioxide and radiocarbon in the natural carbon cycle. II. Changes from A.D. 1700 to 2070 as deduced from a geochemical model, in: Carbon and the Biosphere, Proceedings of the 24th Brookhaven Symposium in Biology, 16-18 May 1972, edited by: Woodwell, G. M. and Pecan, E. V., US Atomic Energy Commission, 86-135, Upton, NY, 1973.

Bates, R. G.: $\mathrm{pH}$ measurements in the marine environment, Pure Appl. Chem., 54, 229-232, doi:10.1351/pac198254010229, 1982.

Bates, R. G. and Culberson, C. H.: Hydrogen ions and the thermodynamic state of marine systems, in: The Fate of Fossil Fuel $\mathrm{CO}_{2}$ in the Oceans, edited by: Andersen, N. R. and Malahoff, A., Plenum Press, New York, NY, 45-61, 1977.

Bolin, B., Björkström, A., Holmén, K., and Moore, B.: The simultaneous use of tracers for ocean circulation studies, Tellus B, 35, 206-236, 1983.

Broecker, W. S. and Peng, T.-H.: Tracers in the Sea, LamontDoherty Geological Observatory of Columbia University, Palisades, NY 10964, 1982.

Buck, R. P., Rondinini, S., Covington, A. K., Baucke, F. G. K., Brett, C. M. A., Camões, M. F., Milton, M. J. T., Mussini, T., Naumann, R., Pratt, K. W., Spitzer, P., and Wilson, G. S.: Measurement of $\mathrm{pH}$. Definition, standards, and procedures (IUPAC Recommendations 2002), Pure Appl. Chem., 74, 2169-2200, doi:10.1351/pac200274112169, 2002.

Bus, J. C. P. and Dekker, T. J.: Two efficient algorithms with guaranteed convergence for finding a zero of a function, ACM T. Math. Software, 1, 330-345, 1975.

Caldeira, K. and Wickett, M. E.: Oceanography: anthropogenic carbon and ocean pH, Nature, 425, p. 365, doi:10.1038/425365a, 2003.

Dickson, A. G.: An exact definition of total alkalinity and a procedure for the estimation of alkalinity and total inorganic carbon from titration data, Deep-Sea Res., 28A, 609-623, 1981.

Dickson, A. G.: pH scales and proton-transfer reactions in saline media such as sea water, Geochim. Cosmochim. Ac., 48, 22992308, 1984.

Dickson, A. G.: Standard potential of the reaction: $\mathrm{AgCl}(\mathrm{s})$ $+\frac{1}{2} \mathrm{H}_{2}(\mathrm{~g})=\mathrm{Ag}(\mathrm{s})+\mathrm{HCl}(\mathrm{aq})$, and the standard acidity constant of the ion $\mathrm{HSO}_{4}^{-}$in synthetic sea water from 273.15 to $318.15 \mathrm{~K}$, J. Chem. Thermodyn., 22, 113-127, doi:10.1016/0021-9614(90)90074-Z, 1990.

Dickson, A. G.: The measurement of sea water pH, Mar. Chem., 44, 131-142, doi:10.1016/0304-4203(93)90198-W, 1993.

Dickson, A. G.: The carbon dioxide system in seawater: equilibrium chemistry and measurements, in: Guide to best practices for ocean acidification research and data reporting, edited by: Riebesell, U., Fabry, V. J., Hansson, L., and Gattuso, J.-P., Publications Office of the European Union, Luxembourg, 17-40, doi:10.2777/58454, 2010.

Dickson, A. G. and Riley, J. P.: The estimation of acid dissolution constants in seawater media from potentiometric titrations with strong base. I. The ionic product of water $-K_{\mathrm{W}}$, Mar. Chem., 7 , 89-99, 1979.
Dickson, A. G., Sabine, C. L., and Christian, J. R., editors.: Guide to Best Practices for Ocean $\mathrm{CO}_{2}$ Measurements, vol. 3 of PICES Special Publication, Carbon Dioxide Information and Analysis Center, Oak Ridge (TN), available at: http://cdiac.ornl.gov/ oceans/Handbook_2007.html, last access: 11 September 2012, 2007.

Doney, S. C., Lindsay, K., Fung, I., and John, J.: Natural variability in a stable, 1000-yr global coupled climate-carbon cycle simulation, J. Climate, 19, 3033-3054, doi:10.1175/JCLI3783.1, 2006.

Dowell, M. and Jarrett, P.: A modified regula falsi method for computing the root of an equation, BIT, 11, 168-174, 1971.

Dyrssen, D. W.: Framvaren and the Black Sea - similarities and differences, Aquat. Geochem., 5, 59-73, doi:10.1023/A:1009663704604, 1999.

Follows, M. J., Ito, T., and Dutkiewicz, S.: On the solution of the carbonate chemistry system in ocean biogeochemistry models, Ocean Model., 12, 290-301, doi:10.1016/j.ocemod.2005.05.004, 2006.

Gangst $\varnothing$, R., Joos, F., and Gehlen, M.: Sensitivity of pelagic calcification to ocean acidification, Biogeosciences, 8, 433-458, doi:10.5194/bg-8-433-2011, 2011.

Goosse, H., Brovkin, V., Fichefet, T., Haarsma, R., Huybrechts, P., Jongma, J., Mouchet, A., Selten, F., Barriat, P.-Y., Campin, J.M., Deleersnijder, E., Driesschaert, E., Goelzer, H., Janssens, I., Loutre, M.-F., Morales Maqueda, M. A., Opsteegh, T., Mathieu, P.-P., Munhoven, G., Pettersson, E. J., Renssen, H., Roche, D. M., Schaeffer, M., Tartinville, B., Timmermann, A., and Weber, S. L.: Description of the Earth system model of intermediate complexity LOVECLIM version 1.2, Geosci. Model Dev., 3, 603-633, doi:10.5194/gmd-3-603-2010, 2010.

Hansson, I.: A new set of $\mathrm{pH}$-scales and standard buffers for sea water, Deep-Sea Res., 20, 479-491, 1973.

Heinze, C., Maier-Reimer, E., and Winn, K.: Glacial $p \mathrm{CO}_{2}$ reduction by the World Ocean: experiments with the Hamburg Carbon Cycle Model, Paleoceanography, 6, 395-430, 1991.

Hoffert, M. I., Wey, Y.-C., Callegari, A. J., and Broecker, W. S.: Atmospheric response to deep-sea injections of fossil-fuel carbon dioxide, Climatic Change, 2, 53-68, doi:10.1007/BF00138226, 1979.

Hofmann, A. F., Soetaert, K., Middelburg, J. J., and Meysman, F. J. R.: AquaEnv: An Aquatic Acid-Base Modelling Environment in R, Aquat. Geochem., 16, 507-546, doi:10.1007/s10498-009-9084-1, 2010.

Hofmann, A. F., Soetaert, K., and Meysman, F. J.: AquaEnv: AquaEnv - an integrated development toolbox for aquatic chemical model generation. $\mathrm{R}$ package version 1.0-3., available at: http://cran.r-project.org/web/packages/AquaEnv/index.html, last access: 29 May 2013, 2012.

Keeling, C. D.: The carbon dioxide cycle: reservoir models to depict the exchange of atmospheric carbon dioxide with the oceans and land plants, in: Chemistry of the Lower Atmosphere, chap. 6, edited by: Rasool, S. I., Plenum Press, New York, NY, 251-329, 1973.

Khoo, K. H., Ramette, R. W., Culberson, C. H., and Bates, R. G.: Determination of hydrogen ion concentrations in seawater from 5 to $40{ }^{\circ} \mathrm{C}$ : Standard potentials at salinities from 20 to $45 \%$, Anal. Chem., 49, 29-34, doi:10.1021/ac50009a016, 1977.

Kirby, C. S. and Cravotta III, C. A.: Net alkalinity and net acidity. 1: Theoretical considerations, Appl. Geochem., 20, 1920-1940, 
doi:10.1016/j.apgeochem.2005.07.002, 2005.

Lavigne, H. and Gattuso, J.-P.: Seacarb: Seawater Carbonate Chemistry with $\mathrm{R}, \mathrm{R}$ Package Version 2.4., available at: http:// cran.r-project.org/web/packages/seacarb/index.html, last access: 13 December 2012, 2012.

Le Hir, G., Donnadieu, Y., Yves Goddéris, Y., Pierrehumbert, R. T., Halverson, G. T., Macouin, M., Nédélec, A., and Ramstein, G.: The snowball Earth aftermath: exploring the limits of continental weathering processes, Earth Planet. Sc. Lett., 277, 453-463, doi:10.1016/j.epsl.2008.11.010, 2009.

Lewis, E. and Wallace, D.: Program Developed for $\mathrm{CO}_{2}$ System Calculations, Tech. Rep. 105, Carbon Dioxide Analysis Center, Oak Ridge National Laboratory, Oak Ridge (TN), 1998.

Luff, R., Haeckel, M., and Wallmann, K.: Robust and fast FORTRAN and MATLAB libraries to calculate $\mathrm{pH}$ distributions in marine systems, Comput. Geosci., 27, 157-169, 2001.

Maier-Reimer, E.: Geochemical cycles in an Ocean General Circulation Model. Preindustrial tracer distributions, Global Biogeochem. Сy., 7, 645-677, 1993.

Maier-Reimer, E. and Hasselmann, K.: Transport and storage of $\mathrm{CO}_{2}$ in the ocean - an inorganic ocean-circulation carbon cycle model, Clim. Dynam., 2, 63-90, 1987.

Maier-Reimer, E., Kriest, I., Segschneider, J., and Wetzel, P.: The HAMburg Ocean Carbon Cycle Model HAMOCC 5.1 - Technical Description Release 1.1, Berichte zur Erdsystemforschung, Reports on Earth System Science 14, Max-Planck-Institut für Meteorologie, Hamburg, Germany, 2005.

Marchal, O., Stocker, T. F., and Joos, F.: A latitude-depth, circulation-biogeochemical ocean model for paleoclimate studies. Development and sensitivities, Tellus B, 50, 290-316, doi:10.1034/j.1600-0889.1998.t01-2-00006.x, 1998.

Marion, G. M., Millero, F. J., Camões, M. F., Spitzer, P., Feistel, R., and Chen, C.-T. A.: pH of seawater, Mar. Chem., 126, 89-96, doi:10.1016/j.marchem.2011.04.002, 2011.

Millero, F. J. and Sohn, M. L.: Chemical Oceanography, CRC Press, Boca Raton, Florida, 531 pp., 1992.

Millero, F. J., Feistel, R., Wright, D. G., and McDougall, T. J.: The composition of standard seawater and the definition of the reference-composition salinity scale, Deep-Sea Res. Pt. I, 55, 50-72, doi:10.1016/j.dsr.2007.10.001, 2008.

Millero, F. J., Woosley, R., DiTrolio, B., and Waters, J.: Effect of ocean acidification on the speciation of metals in seawater, Oceanography, 22, 72-85, doi:10.5670/oceanog.2009.98, 2009.

Müller, S. A., Joos, F., Plattner, G.-K., Edwards, N. R., and Stocker, T. F.: Modeled natural and excess radiocarbon: sensitivities to the gas exchange formulation and ocean transport strength, Global Biogeochem. Cy., 22, GB3011, doi:10.1029/2007GB003065, 2008.

Munhoven, G.: Modelling Glacial-Interglacial Atmospheric $\mathrm{CO}_{2}$ Variations: The Role of Continental Weathering, Ph.D. thesis, Université de Liège, Liège, available at: http://www.astro. ulg.ac.be/ $\sim$ munhoven/en/PhDThesis.pdf (last access: 21 February 2013), 1997.

Munhoven, G.: Glacial-interglacial rain ratio changes: implications for atmospheric $\mathrm{CO}_{2}$ and ocean-sediment interaction, Deep-Sea Res. Pt. II, 54, 722-746, doi:10.1016/j.dsr2.2007.01.008, 2007.

Munhoven, G.: Future CCD and CSH variations: deep-sea impact of ocean acidification, Geochim. Cosmochim. Ac., 73, p. A917, 2009.
Munhoven, G. and François, L. M.: Glacial-interglacial variability of atmospheric $\mathrm{CO}_{2}$ due to changing continental silicate rock weathering: a model study, J. Geophys. Res., 101, 21423-21437, doi:10.1029/96JD01842, 1996.

Opdyke, B. N. and Walker, J. C. G.: Return of the coral reef hypothesis: basin to shelf partitioning of $\mathrm{CaCO}_{3}$ and its effect on atmospheric $\mathrm{CO}_{2}$, Geology, 20, 733-736, 1992.

Orr, J., Najjar, R., Sabine, C., and Joos, F.: Abiotic-HOWTO, available at: http://ocmip5.ipsl.jussieu.fr/OCMIP/phase2/simulations/ Abiotic/HOWTO-Abiotic.html, last access: 20 July 2012, 2000.

Palmer, J. R. and Totterdell, I. J.: Production and export in a global ocean ecosystem model, Deep-Sea Res. Pt. I, 48, 1169-1198, doi:10.1016/S0967-0637(00)00080-7, 2001.

Park, P. K.: Oceanic $\mathrm{CO}_{2}$ system: an evaluation of ten methods of investigation, Limnol. Oceanogr., 14, 179-186, 1969.

Peng, T.-H., Takahashi, T., Broecker, W. S., and Olafsson, J.: Seasonal variability of carbon dioxide, nutrients and oxygen in the northern North Atlantic surface water: observations and a model, Tellus B, 39, 439-458, 1987.

Press, W. H., Flannery, B. P., Teukolsky, S. A., and Vetterling, W. T.: Numerical Recipes (FORTRAN Version), Cambridge University Press, Cambridge, 1989.

Ridgwell, A. J.: Glacial-Interglacial Pertubations of the Global Carbon Cycle, Ph.D. thesis, University of East Anglia, Norwich, 2001.

Ridgwell, A. and Schmidt, D. N.: Past constraints on the vulnerability of marine calcifiers to massive carbon dioxide release, Nat Geosci., 3, 196-200, doi:10.1038/ngeo755, 2010.

Ridgwell, A., Hargreaves, J. C., Edwards, N. R., Annan, J. D., Lenton, T. M., Marsh, R., Yool, A., and Watson, A.: Marine geochemical data assimilation in an efficient Earth System Model of global biogeochemical cycling, Biogeosciences, 4, 87-104, doi:10.5194/bg-4-87-2007, 2007.

Shaffer, G., Malskær Olsen, S., and Pepke Pedersen, J. O.: Presentation, calibration and validation of the low-order, DCESS Earth System Model (Version 1), Geosci. Model Dev., 1, 17-51, doi:10.5194/gmd-1-17-2008, 2008.

Walker, J. C. G. and Opdyke, B. N.: Influence of variable rates of neritic carbonate deposition on atmospheric carbon dioxide and pelagic sediments, Paleoceanography, 10, 415-427, 1995.

Waters, J. F. and Millero, F. J.: The free proton concentration scale for seawater $\mathrm{pH}$, Mar. Chem., 149, 8-22, doi:10.1016/j.marchem.2012.11.003, 2013.

Wolf-Gladrow, D. A., Zeebe, R. E., Klaas, C., Körtzinger, A., and Dickson, A. G.: Total alkalinity: the explicit conservative expression and its application to biogeochemical processes, Mar. Chem., 106, 287-300, doi:10.1016/j.marchem.2007.01.006, 2007.

Yao, W. and Millero, F. J.: The chemistry of the anoxic waters in the Framvaren Fjord, Norway, Aquat. Geochem., 1, 53-88, 1995.

Zeebe, R. E.: LOSCAR: Long-term Ocean-atmosphere-Sediment CArbon cycle Reservoir Model v2.0.4, Geosci. Model Dev., 5, 149-166, doi:10.5194/gmd-5-149-2012, 2012.

Zeebe, R. E. and Wolf-Gladrow, D.: $\mathrm{CO}_{2}$ in seawater: equilibrium, kinetics, isotopes, vol. 65 of Elsevier Oceanography Series, Elsevier, Amsterdam (NL), 2001. 